\title{
Diverse Synthesis of Novel Bis-terpyridines via Suzuki-Type Cross-Coupling
}

\author{
Fu She Han, Masayoshi Higuchi, Dirk G. Kurth \\ Functional Modules Group, Organic Nanomaterials Center, National Institute for Materials Science, \\ 1-1 Namiki, Tsukuba, Ibaraki 305-0044, Japan
}

1. Synthesis of mono-terpyridines $\mathbf{4}$ and $\mathbf{5}$ (taking the synthesis of $\mathbf{5}$ as a typical example): To a 120 $\mathrm{mL}$ MeOH solution of 4-bromobenzaldehyde $\mathbf{1}(1.0 \mathrm{~g}, 5.40 \mathrm{mmol})$ was added 2-acetyl-6-bromopyridine 3 (2.2 g, $10.80 \mathrm{mmol}), \mathrm{NaOH}(0.22 \mathrm{~g}, 5.40 \mathrm{mmol})$, and $30 \mathrm{~mL}$ concentrated $\mathrm{NH}_{4} \mathrm{OH}$ (aq.). The reaction mixture was refluxed for 2.5 days. The oil-bath was then removed, and the reaction mixture was stirred at ambient temperature for $3 \mathrm{~h}$. The slight yellow precipitate that was formed upon cooling was filtered and washed sequentially with de-ionized $\mathrm{H}_{2} \mathrm{O}$ and $\mathrm{MeOH}$. The precipitate collected from the filtration was then purified by column chromatography on activated basic $\mathrm{Al}_{2} \mathrm{O}_{3}$ (hexane/ $\mathrm{CH}_{2} \mathrm{Cl}_{2}$ 1:1) to give $\mathbf{5}$ as white powder $(2.12 \mathrm{~g}, 72 \%) .{ }^{1} \mathrm{H}-\mathrm{NMR}\left(300 \mathrm{MHz}, \mathrm{CDCl}_{3}\right) \delta=8.64(\mathrm{~s}, 2 \mathrm{H}), 8.57\left(\mathrm{dd}, 2 \mathrm{H}, J_{I}=7.8 \mathrm{~Hz}, J_{2}=0.9\right.$ $\mathrm{Hz}), 7.75-7.65(\mathrm{~m}, 6 \mathrm{H}), 7.54\left(\mathrm{dd}, 2 \mathrm{H}, J_{1}=7.8 \mathrm{~Hz}, J_{2}=0.9 \mathrm{~Hz}\right) ;{ }^{13} \mathrm{C}-\mathrm{NMR}\left(75 \mathrm{MHz}, \mathrm{CDCl}_{3}\right) \delta=157.0$, 154.6, 149.5, 141.7, 139.1, 137.0, 132.2, 128.9, 128.3, 123.7, 120.0, 119.5; MALDI-MS (\%): $\mathrm{m} / \mathrm{z}=546$ (100) $[\mathrm{M}+\mathrm{H}], 568(100)[\mathrm{M}+\mathrm{Na}], 584(90)[\mathrm{M}+\mathrm{K}]$; HRMS: found m/z $567.8469[\mathrm{M}+\mathrm{Na}] ; \mathrm{C}_{21} \mathrm{H}_{12} \mathrm{Br}_{3} \mathrm{~N}_{3} \mathrm{Na}$ requires 567.8459 .

2. Synthesis of 6,6"-dicarbonitrile mono-terpyridine 7: $\mathrm{To}$ a $100 \mathrm{~mL} \mathrm{CH}_{2} \mathrm{Cl}_{2}$ solution of $\mathbf{4}(1.13 \mathrm{~g}, 2.58$ mmol $)$ was added $m$-CPBA $(2.0 \mathrm{~g}, 10.30 \mathrm{mmol})$ at $0{ }^{\circ} \mathrm{C}$. The ice-bath was then removed and the reaction mixture was allowed to stir at room temperature for $22 \mathrm{~h} .100 \mathrm{~mL}$ saturated aqueous $\mathrm{Na}_{2} \mathrm{CO}_{3}$ was added 
slowly to the reaction mixture and stirred for additional $20 \mathrm{~min}$ at room temperature. The biphasic solution was separated and the organic layer was washed with saturated aqueous $\mathrm{Na}_{2} \mathrm{CO}_{3}$ for three times. The separated organic layer was then dried over $\mathrm{MgSO}_{4}$, filtered, concentrated, and purified by column chromatography on silica gel $\left(\mathrm{CH}_{2} \mathrm{Cl}_{2} / \mathrm{MeOH} 98: 2\right)$ to give $\mathbf{6}(1.31 \mathrm{~g}, 96 \%)$. The obtained 6 was dissolved in $150 \mathrm{~mL} \mathrm{CH}_{2} \mathrm{Cl}_{2}$ and the solution was allowed to stir at room temperature for $20 \mathrm{~h}$ after the addition of trimethylsilylcyanide $(4.2 \mathrm{~mL}, 31.19 \mathrm{mmol})$ and acetylchloride $(1.33 \mathrm{~mL}, 18.71 \mathrm{mmol}) .100 \mathrm{~mL}$ saturated aqueous $\mathrm{Na}_{2} \mathrm{CO}_{3}$ was added slowly to the reaction mixture and stirred for additional 20 min at room temperature. The biphasic solution was separated and the organic layer was washed with saturated aqueous $\mathrm{Na}_{2} \mathrm{CO}_{3}$ for three times. The separated organic layer was then dried over $\mathrm{MgSO}_{4}$, filtered, concentrated, and purified by column chromatography on silica gel (hexane/ $\mathrm{CH}_{2} \mathrm{Cl}_{2}=1: 1$, then pure $\mathrm{CH}_{2} \mathrm{Cl}_{2}$ ) to give 7 as white solid (1.19 g, 88\%). ${ }^{1} \mathrm{H}-\mathrm{NMR}\left(300 \mathrm{MHz}, \mathrm{CDCl}_{3}\right) \delta=8.85(\mathrm{~d}, 2 \mathrm{H}, J=8.4 \mathrm{~Hz})$, 8.79 (s, $2 \mathrm{H}), 8.02$ (t, $2 \mathrm{H}, J=7.8 \mathrm{~Hz}), 7.78$ (d, $2 \mathrm{H}, J=8.4 \mathrm{~Hz}), 7.77$ (d, $2 \mathrm{H}, J=7.8 \mathrm{~Hz}), 7.71$ (d, $2 \mathrm{H}, J$ $=8.4 \mathrm{~Hz}) ;{ }^{13} \mathrm{C}-\mathrm{NMR}\left(75 \mathrm{MHz}, \mathrm{CDCl}_{3}\right) \delta=157.3,154.3,149.9,138.0,136.5,133.4,132.5,128.8,128.5$, 124.3, 124.2, 120.0, 117.3; MALDI-MS (\%): $\mathrm{m} / \mathrm{z}=437$ (90) [M], $460(100)[\mathrm{M}+\mathrm{Na}]$. HRMS: found m/z $460.0153[\mathrm{M}+\mathrm{Na}] ; \mathrm{C}_{23} \mathrm{H}_{12} \mathrm{BrN}_{5} \mathrm{Na}$ requires 460.0174 .

3. Synthesis of 6,6"-dimethoxyl mono-terpyridine 8: To a $80 \mathrm{~mL}$ dioxane solution of 5 (960 mg, 1.75 mmol) was added $\mathrm{NaOMe}(1.0 \mathrm{M}$ solution in $\mathrm{MeOH}, 10.51 \mathrm{mmol})$ under $\mathrm{N}_{2}$ atmosphere. The solution was then stirred at $100{ }^{\circ} \mathrm{C}$ for 2 days. Solvent was evaporated, and the residue was suspended in $150 \mathrm{~mL}$ $\mathrm{CHCl}_{3}$, then washed with de-ionized $\mathrm{H}_{2} \mathrm{O}$ for three times. The organic layer was dried over $\mathrm{MgSO} 4$, filtered, concentrated, and purified by column chromatography on activated basic $\mathrm{Al}_{2} \mathrm{O}_{3}$ (hexane $/ \mathrm{CH}_{2} \mathrm{Cl}_{2}$ $=2: 1)$ to give $8(785 \mathrm{mg}, 100 \%) .{ }^{1} \mathrm{H}-\mathrm{NMR}\left(300 \mathrm{MHz}, \mathrm{CDCl}_{3}\right) \delta=8.60(\mathrm{~s}, 2 \mathrm{H}), 8.27(\mathrm{~d}, 2 \mathrm{H}, J=7.5 \mathrm{~Hz})$, $7.76(\mathrm{t}, 2 \mathrm{H}, J=8.4 \mathrm{~Hz}), 7.68(\mathrm{br}, 4 \mathrm{H}), 6.80(\mathrm{~d}, 2 \mathrm{H}, J=8.4 \mathrm{~Hz}), 4.08(\mathrm{~s}, 6 \mathrm{H}) ;{ }^{13} \mathrm{C}-\mathrm{NMR}(75 \mathrm{MHz}$, $\left.\mathrm{CDCl}_{3}\right) \delta=163.6,156.0,153.4,148.8,139.4,138.2,132.2,128.8,123.3,118.4,114.1,111.2,53.3 ;$ 
MALDI-MS (\%): $\mathrm{m} / \mathrm{z}=448(100)[\mathrm{M}+\mathrm{H}]$. HRMS: found $\mathrm{m} / \mathrm{z} 470.0483[\mathrm{M}+\mathrm{Na}] ; \mathrm{C}_{21} \mathrm{H}_{12} \mathrm{Br}_{3} \mathrm{~N}_{3} \mathrm{Na}$ requires 470.0480 .

4. General procedure for the synthesis of symmetric bis-terpyridines 14a-c: To a $30 \mathrm{~mL}$ DMSO solution of mono-terpyridine $(4,5,7$ or $\mathbf{8}, 0.773 \mathrm{mmol})$ was added bispinacolatodiboron 13 (102 $\mathrm{mg}$, $0.402 \mathrm{mmol}), \mathrm{K}_{2} \mathrm{CO}_{3}(320 \mathrm{mg}, 2.318 \mathrm{mmol})$ and $\mathrm{PdCl}_{2}\left(\mathrm{PPh}_{3}\right)_{2}(27 \mathrm{mg}, 0.039 \mathrm{mmol})$. The solution was stirred at 80 to $120^{\circ} \mathrm{C}$ under an argon atmosphere until the starting material was disappeared as monitored by TLC. The catalyst was removed by filtration and washed with $\mathrm{CHCl}_{3}$ after the reaction mixture was cooled to room temperature. The filtrate was then washed with de-ionized $\mathrm{H}_{2} \mathrm{O}(50 \mathrm{~mL})$ for five times, and the organic layer was dried over $\mathrm{MgSO}_{4}$, filtered, concentrated and purified by column chromatography on activated basic $\mathrm{Al}_{2} \mathrm{O}_{3}$ to give the dimerized products $14 a-c$.

14a: ${ }^{1} \mathrm{H}-\mathrm{NMR}\left(300 \mathrm{MHz}, \mathrm{CDCl}_{3}\right) \delta=8.82(\mathrm{~s}, 4 \mathrm{H}), 8.75\left(\mathrm{ddd}, 4 \mathrm{H}, J_{l}=5.4 \mathrm{~Hz}, J_{2}=1.8 \mathrm{~Hz}, J_{3}=0.9 \mathrm{~Hz}\right)$, $8.69(\mathrm{~d}, 4 \mathrm{H}, J=7.8 \mathrm{~Hz}), 8.04(\mathrm{~d}, 4 \mathrm{H}, J=8.1 \mathrm{~Hz}), 7.89\left(\mathrm{ddd}, 4 \mathrm{H}, J_{1}=8.1 \mathrm{~Hz}, J_{2}=8.1 \mathrm{~Hz}, J_{3}=1.8 \mathrm{~Hz}\right)$, $7.83(\mathrm{~d}, 4 \mathrm{H}, J=8.4 \mathrm{~Hz}), 7.37\left(\mathrm{dd}, 4 \mathrm{H}, J_{l}=7.8 \mathrm{~Hz}, J_{2}=7.8 \mathrm{~Hz}\right) ;{ }^{13} \mathrm{C}-\mathrm{NMR}\left(75 \mathrm{MHz}, \mathrm{CDCl}_{3}\right) \delta=156.3$, $156.1,149.7,149.2,141.1,137.7,136.9,127.8,127.6,123.8,121.4,118.8 ;$ MALDI-MS: m/z $(\%)=617$ (100) $[\mathrm{M}+\mathrm{H}]$; HRMS: found $\mathrm{m} / \mathrm{z} 617.2470[\mathrm{M}+\mathrm{H}] ; \mathrm{C}_{42} \mathrm{H}_{29} \mathrm{~N}_{6}$ requires 617.2454.

14b: MALDI-MS (\%): m/z = $717(100)[\mathrm{M}+\mathrm{H}]$.

14c: ${ }^{1} \mathrm{H}-\mathrm{NMR}\left(300 \mathrm{MHz}, \mathrm{CDCl}_{3}\right) \delta=8.72(\mathrm{~s}, 4 \mathrm{H}), 8.30(\mathrm{~d}, 4 \mathrm{H}, J=7.2 \mathrm{~Hz}), 7.98(\mathrm{~d}, 4 \mathrm{H}, J=8.4 \mathrm{~Hz})$, $7.87(\mathrm{~d}, 4 \mathrm{H}, J=8.4 \mathrm{~Hz}), 7.78(\mathrm{dd}, 4 \mathrm{H}, J=7.2 \mathrm{~Hz}), 6.83(\mathrm{~d}, 4 \mathrm{H}, J=8.1 \mathrm{~Hz}), 4.12(\mathrm{~s}, 12 \mathrm{H}) ;{ }^{13} \mathrm{C}-\mathrm{NMR}$ $\left(75 \mathrm{MHz}, \mathrm{CDCl}_{3}\right) \delta=163.8,156.1,153.9,139.4,130.8,128.8,127.8,127.7,127.4,118.6,114.2,111.1$, 53.3; MALDI-MS (\%): $\mathrm{m} / \mathrm{z}=737$ (100) $[\mathrm{M}+\mathrm{H}]$; HRMS: found $\mathrm{m} / \mathrm{z} 737.2875[\mathrm{M}+\mathrm{H}] ; \mathrm{C}_{46} \mathrm{H}_{37} \mathrm{~N}_{6} \mathrm{O}_{4}$ requires 737.2876 .

5. General procedure for the synthesis of unsymmetric bis-terpyridines 15a-b: To a $8 \mathrm{~mL}$ DMSO 
solution of 4 (100 mg, $0.258 \mathrm{mmol})$ was added bispinacolatodiboron 13 (72 mg, $0.283 \mathrm{mmol})$, KOAc (76 $\mathrm{mg}, 0.773 \mathrm{mmol})$ and $\mathrm{PdCl}_{2}\left(\mathrm{PPh}_{3}\right)_{2}(9.0 \mathrm{mg}, 0.013 \mathrm{mmol})$. The solution was stirred at $80{ }^{\circ} \mathrm{C}$ under argon atmosphere $12 \mathrm{~h}$. The reaction vessel was recharged with $\mathrm{K}_{2} \mathrm{CO}_{3}$ (107 mg, $\left.0.773 \mathrm{mmol}\right), 7$ (or 8) $(0.258$ mmol) and catalyst $(5 \% \mathrm{~mol})$ after being diluted with another $8 \mathrm{~mL}$ DMSO. The mixture was then heated at $80-120{ }^{\circ} \mathrm{C}$ until 7 (or 8) was disappeared as monitored by TLC. The catalyst was removed by filtration and washed with $\mathrm{CHCl}_{3}$ after the reaction mixture was cooled to room temperature. The filtrate was then washed with de-ionized $\mathrm{H}_{2} \mathrm{O}(50 \mathrm{~mL})$ for five times, and the organic layer was dried over $\mathrm{MgSO}_{4}$, filtered, concentrated and purified by column chromatography on activated basic $\mathrm{Al}_{2} \mathrm{O}_{3}$ to give $\mathbf{1 5 a - b}$.

15a: ${ }^{1} \mathrm{H}-\mathrm{NMR}\left(300 \mathrm{MHz}, \mathrm{CDCl}_{3}\right) \delta=8.90(\mathrm{~s}, 2 \mathrm{H}), 8.88\left(\mathrm{dd}, 2 \mathrm{H}, J_{l}=8.1 \mathrm{~Hz}, J_{2}=1.2 \mathrm{~Hz}\right), 8.83(\mathrm{~s}, 2 \mathrm{H})$, $8.76\left(\mathrm{dd}, 2 \mathrm{H}, J_{1}=3.6 \mathrm{~Hz}, J_{2}=0.9 \mathrm{~Hz}\right), 8.70(\mathrm{~d}, 2 \mathrm{H}, J=8.1 \mathrm{~Hz}), 8.08-8.01(\mathrm{~m}, 6 \mathrm{H}), 7.92-7.87(\mathrm{~m}, 4$ $\mathrm{H}), 7.85(\mathrm{~d}, 2 \mathrm{H}, J=8.1 \mathrm{~Hz}), 7.78\left(\mathrm{dd}, 2 \mathrm{H}, J_{1}=7.8 \mathrm{~Hz}, J_{2}=1.2 \mathrm{~Hz}\right), 7.37\left(\mathrm{ddd}, 2 \mathrm{H}, J_{1}=J_{2}=7.5 \mathrm{~Hz}, J_{3}\right.$ $=1.8 \mathrm{~Hz}) ;{ }^{13} \mathrm{C}-\mathrm{NMR}\left(75 \mathrm{MHz}, \mathrm{CDCl}_{3}\right) \delta=157.6,156.5,156.2,154.3,149.2,141.9,140.9,137.9,136.8$ (2C), 133.6, 132.7, 130.8, 128.8, 128.4, 128.0 (2C), 127.9, 127.7, 124.4, 123.8, 121.4, 120.3, 118.9, 117.3; ; MALDI-MS (\%): m/z = $667(100)[\mathrm{M}+\mathrm{H}]$; HRMS: found $\mathrm{m} / \mathrm{z} 667.2383[\mathrm{M}+\mathrm{H}] ; \mathrm{C}_{44} \mathrm{H}_{27} \mathrm{~N}_{8}$ requires 667.2359 .

15b: ${ }^{1} \mathrm{H}-\mathrm{NMR}\left(300 \mathrm{MHz}, \mathrm{CDCl}_{3}\right) \delta=8.82(\mathrm{~s}, 2 \mathrm{H}), 8.75\left(\mathrm{ddd}, 2 \mathrm{H}, J_{I}=5.7 \mathrm{~Hz}, J_{2}=1.8 \mathrm{~Hz}, J_{3}=0.9 \mathrm{~Hz}\right)$, $8.72(\mathrm{~s}, 2 \mathrm{H}), 8.70(\mathrm{~d}, 2 \mathrm{H}, J=7.8 \mathrm{~Hz}), 8.29\left(\mathrm{dd}, 2 \mathrm{H}, J_{I}=7.5 \mathrm{~Hz}, J_{2}=0.9 \mathrm{~Hz}\right), 8.05(\mathrm{~d}, 2 \mathrm{H}, J=7.5 \mathrm{~Hz})$, $7.97(\mathrm{~d}, 2 \mathrm{H}, J=7.2 \mathrm{~Hz}), 7.90\left(\mathrm{ddd}, 2 \mathrm{H}, J_{I}=J_{2}=7.8 \mathrm{~Hz}, J_{3}=1.8 \mathrm{~Hz}\right), 7.87(\mathrm{~d}, 2 \mathrm{H}, J=8.7 \mathrm{~Hz}), 7.81(\mathrm{~d}$, $2 \mathrm{H}, J=6.9 \mathrm{~Hz}), 7.76(\mathrm{~d}, 2 \mathrm{H}, J=7.8 \mathrm{~Hz}), 7.37\left(\mathrm{dd}, 2 \mathrm{H}, J_{I}=J_{2}=6.6 \mathrm{~Hz}\right), 6.83(\mathrm{~d}, 2 \mathrm{H}, J=7.8 \mathrm{~Hz}), 4.12$ (s, $6 \mathrm{H}) ;{ }^{13} \mathrm{C}-\mathrm{NMR}\left(75 \mathrm{MHz}, \mathrm{CDCl}_{3}\right) \delta=163.6,156.3,156.0,155.9,153.7,149.7,149.4,149.2(2 \mathrm{C})$, 141.0, 139.4, 138.4, 137.7, 136.9, 127.9, 127.7 (2C), 127.6, 123.9, 121.4, 118.7, 118.6, 114.1, 111.1, 53.3; MALDI-MS (\%): $\mathrm{m} / \mathrm{z}=677(100)[\mathrm{M}+\mathrm{H}] ;$ HRMS: found m/z $677.2652[\mathrm{M}+\mathrm{H}] ; \mathrm{C}_{44} \mathrm{H}_{33} \mathrm{~N}_{6} \mathrm{O}_{2}$ requires 677.2665 . 
6. Synthesis of benzene-1,3-diboronate 17: To a $20 \mathrm{~mL}$ DMSO solution of 1,3-dibromobenzene (1.0 g, $4.24 \mathrm{mmol})$ was added bispinacolatodiboron 13 (2.4 g, $9.33 \mathrm{mmol})$, KOAc $(2.1 \mathrm{~g}, 21.19 \mathrm{mmol})$ and $\mathrm{PdCl}_{2}\left(\mathrm{PPh}_{3}\right)_{2}(149 \mathrm{mg}, 0.21 \mathrm{mmol})$, and the solution was stirred at $80{ }^{\circ} \mathrm{C}$ for $24 \mathrm{~h}$. The catalyst was removed by filtration and washed with $\mathrm{CHCl}_{3}$ after the reaction mixture was cooled to room temperature. The filtrate was then washed with de-ionized $\mathrm{H}_{2} \mathrm{O}(50 \mathrm{~mL})$ for five times, and the organic layer was dried over $\mathrm{MgSO}_{4}$, filtered, concentrated and purified by column chromatography on silica gel (hexane/EtOAc $=20: 1)$ to give $17(1.06 \mathrm{~g}, 76 \%) .{ }^{1} \mathrm{H}-\mathrm{NMR}\left(300 \mathrm{MHz}, \mathrm{CDCl}_{3}\right) \delta=8.27(\mathrm{~s}, 1 \mathrm{H}), 7.89\left(\mathrm{dd}, 2 \mathrm{H}, J_{I}=7.2\right.$ $\left.\mathrm{Hz}, J_{2}=1.2 \mathrm{~Hz}\right), 7.36\left(\mathrm{dt}, 1 \mathrm{H}, J_{1}=7.2 \mathrm{~Hz}, J_{2}=1.2 \mathrm{~Hz}\right), 1.34(\mathrm{~s}, 24 \mathrm{H}) ;{ }^{13} \mathrm{C}-\mathrm{NMR}\left(75 \mathrm{MHz}, \mathrm{CDCl}_{3}\right) \delta=$ 141.2, 137.6, 127.0, 83.7, 24.1; MALDI-MS (\%): $\mathrm{m} / \mathrm{z}=353$ (100) [M+Na]; HRMS: found m/z 353.2064 $[\mathrm{M}+\mathrm{Na}] ; \mathrm{C}_{18} \mathrm{H}_{28} \mathrm{~B}_{2} \mathrm{O}_{4} \mathrm{Na}$ requires 353.2072 .

7. General procedure for the synthesis of bis-terpyridines 18a-c: To a $15 \mathrm{~mL}$ DMSO of diboronate $\mathbf{1 7}$ (50 $\mathrm{mg}, 0.152 \mathrm{mmol}$ ) was added mono-terpyridine (4, 7 or $8,2.2$ equiv.), $\mathrm{K}_{2} \mathrm{CO}_{3}$ (5.0 equiv.), and $\mathrm{PdCl}_{2}\left(\mathrm{PPh}_{3}\right)_{2}(10 \mathrm{~mol} \%)$, and the solution was stirred at $80-120{ }^{\circ} \mathrm{C}$ under argon atmosphere until the diboronate 17 was disappeared as monitored by TLC. The catalyst was removed by filtration and washed with $\mathrm{CHCl}_{3}$ after the reaction mixture was cooled to room temperature. The filtrate was then washed with de-ionized $\mathrm{H}_{2} \mathrm{O}(30 \mathrm{~mL})$ for five times, and the organic layer was dried over $\mathrm{MgSO}_{4}$, filtered, concentrated and purified by column chromatography on activated basic $\mathrm{Al}_{2} \mathrm{O}_{3}$ to give the products.

18a: ${ }^{1} \mathrm{H}-\mathrm{NMR}\left(300 \mathrm{MHz}, \mathrm{CDCl}_{3}\right) \delta=8.82(\mathrm{~s}, 4 \mathrm{H}), 8.75\left(\mathrm{ddd}, 4 \mathrm{H}, J_{1}=4.8 \mathrm{~Hz}, J_{2}=1.8 \mathrm{~Hz}, J_{3}=0.9 \mathrm{~Hz}\right)$, $8.69(\mathrm{~d}, 4 \mathrm{H}, J=7.5 \mathrm{~Hz}), 8.05(\mathrm{~d}, 4 \mathrm{H}, J=8.7 \mathrm{~Hz}), 7.98(\mathrm{~s}, 1 \mathrm{H}), 7.89\left(\mathrm{dt}, 4 \mathrm{H}, J_{l}=7.5 \mathrm{~Hz}, J_{2}=1.8 \mathrm{~Hz}\right)$ $7.83(\mathrm{~d}, 4 \mathrm{H}, J=8.7 \mathrm{~Hz}), 7.71\left(\mathrm{dd}, 2 \mathrm{H}, J_{l}=7.5 \mathrm{~Hz}, J_{2}=1.2 \mathrm{~Hz}\right.$ ), $7.60(\mathrm{t}, 1 \mathrm{H}, \mathrm{J}=7.2 \mathrm{~Hz}$ ), 7.37 (ddd, $4 \mathrm{H}$, $\left.J_{1}=7.5 \mathrm{~Hz}, J_{2}=6.3 \mathrm{~Hz}, J_{3}=0.9 \mathrm{~Hz}\right) ;{ }^{13} \mathrm{C}-\mathrm{NMR}\left(75 \mathrm{MHz}, \mathrm{CDCl}_{3}\right) \delta=156.3,156.0,149.7,149.1,141.7$, $141.1,137.5,136.8,129.4,127.8,127.7,126.5,126.0,123.8,121.4,118.7 ;$ MALDI-MS (\%): $\mathrm{m} / \mathrm{z}=693$ (100) $[\mathrm{M}+\mathrm{H}]$; HRMS: found $\mathrm{m} / \mathrm{z} 715.2563[\mathrm{M}+\mathrm{Na}] ; \mathrm{C}_{48} \mathrm{H}_{32} \mathrm{~N}_{6} \mathrm{Na}$ requires 715.2563. 
18b: ${ }^{1} \mathrm{H}-\mathrm{NMR}\left(300 \mathrm{MHz}, \mathrm{CDCl}_{3}\right) \delta=8.90(\mathrm{~s}, 4 \mathrm{H}), 8.88\left(\mathrm{dd}, 4 \mathrm{H}, J_{I}=8.4 \mathrm{~Hz}, J_{2}=1.2 \mathrm{~Hz}\right), 8.07-8.03(\mathrm{~m}$, $8 \mathrm{H}), 8.00(\mathrm{~s}, 1 \mathrm{H}), 7.91\left(\mathrm{dd}, 4 \mathrm{H}, J_{1}=6.9 \mathrm{~Hz}, J_{2}=2.1 \mathrm{~Hz}\right), 7.78\left(\mathrm{dd}, 4 \mathrm{H}, J_{l}=7.8 \mathrm{~Hz}, J_{2}=1.2 \mathrm{~Hz}\right), 7.73$ $\left(\mathrm{dd}, 2 \mathrm{H}, J_{1}=6.9 \mathrm{~Hz}, J_{2}=1.2 \mathrm{~Hz}\right), 7.65(\mathrm{~d}, 1 \mathrm{H}, J=6.9 \mathrm{~Hz}) ;{ }^{13} \mathrm{C}-\mathrm{NMR}\left(75 \mathrm{MHz}, \mathrm{CDCl}_{3}\right) \delta=157.6$, $154.3,150.8,142.5,141.2,137.9,136.8,133.6,130.8,129.6,128.3,128.1,127.9,126.7,124.3,120.3$, 117.3; MALDI-MS (\%): $\mathrm{m} / \mathrm{z}=793(100)[\mathrm{M}+\mathrm{H}]$; HRMS: found m/z 815.2391 [M+Na]; $\mathrm{C}_{52} \mathrm{H}_{28} \mathrm{~N}_{10} \mathrm{Na}$ requires 815.2396.

18c: ${ }^{1} \mathrm{H}-\mathrm{NMR}\left(300 \mathrm{MHz}, \mathrm{CDCl}_{3}\right) \delta=8.72(\mathrm{~s}, 4 \mathrm{H}), 8.29(\mathrm{~d}, 4 \mathrm{H}, J=7.5 \mathrm{~Hz}), 7.97(\mathrm{~d}, 4 \mathrm{H}, J=8.1 \mathrm{~Hz})$, 7.96 (s, $1 \mathrm{H}), 7.86(\mathrm{~d}, 4 \mathrm{H}, J=8.1 \mathrm{~Hz}), 7.77(\mathrm{t}, 4 \mathrm{H}, J=8.1 \mathrm{~Hz}), 7.71\left(\mathrm{dd}, 2 \mathrm{H}, J_{I}=6.9 \mathrm{~Hz}, J_{2}=1.2 \mathrm{~Hz}\right)$, $7.62(\mathrm{t}, 1 \mathrm{H}, J=6.9 \mathrm{~Hz}), 6.83(\mathrm{~d}, 4 \mathrm{H}, J=7.5 \mathrm{~Hz}), 4.11(\mathrm{~s}, 12 \mathrm{H}) ;{ }^{13} \mathrm{C}-\mathrm{NMR}\left(75 \mathrm{MHz}, \mathrm{CDCl}_{3}\right) \delta=163.7$, $156.0,153.8,149.5,141.7,141.3,139.4,138.5,129.5,127.9,127.8,126.5,126.1,118.6,114.2,111.1$, 53.3; MALDI-MS (\%): $\mathrm{m} / \mathrm{z}=813(100)[\mathrm{M}+\mathrm{H}]$; HRMS: found $\mathrm{m} / \mathrm{z} 813.3207[\mathrm{M}+\mathrm{H}] ; \mathrm{C}_{52} \mathrm{H}_{41} \mathrm{~N}_{6} \mathrm{O}_{4}$ requires 813.3207. 


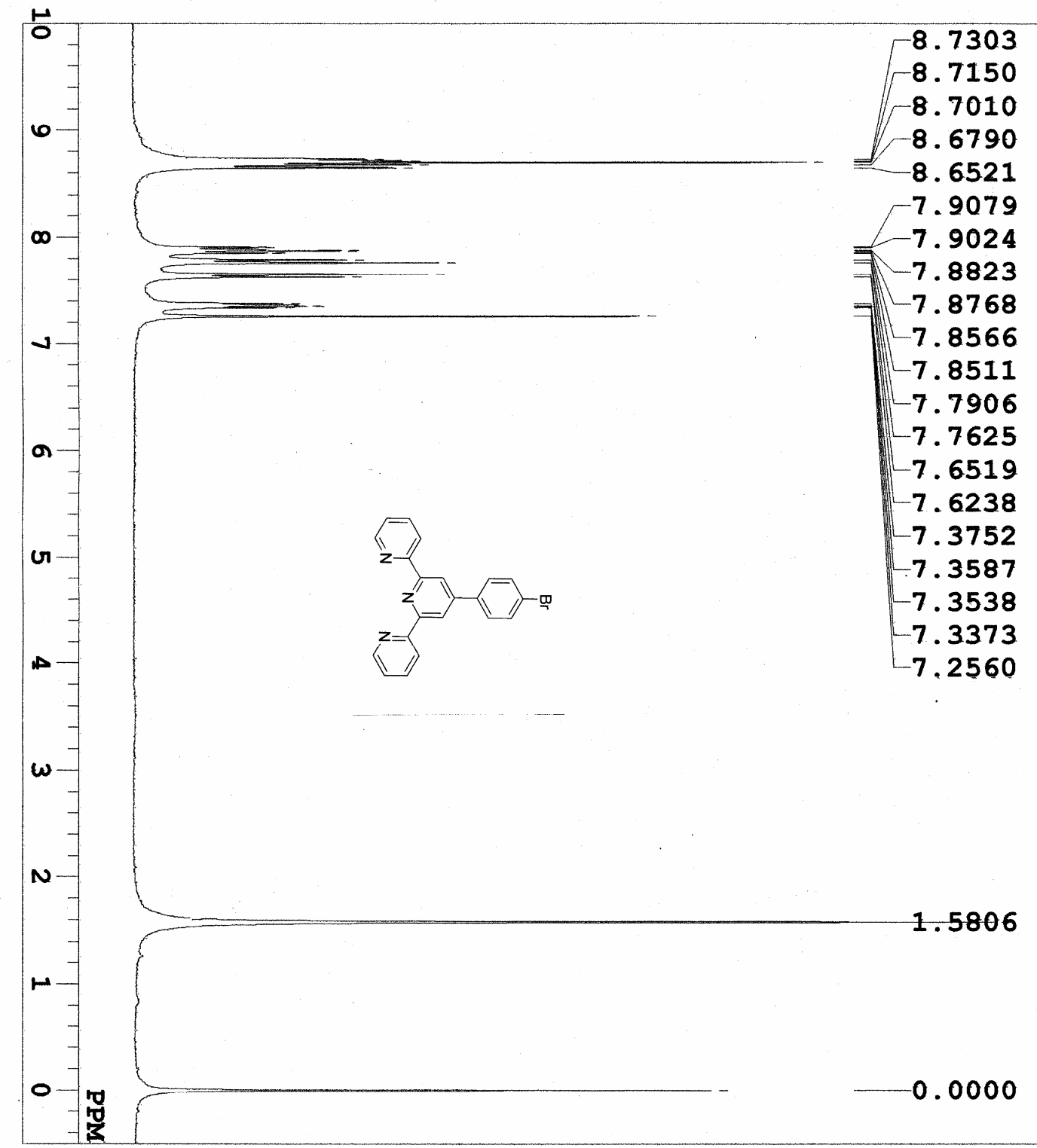

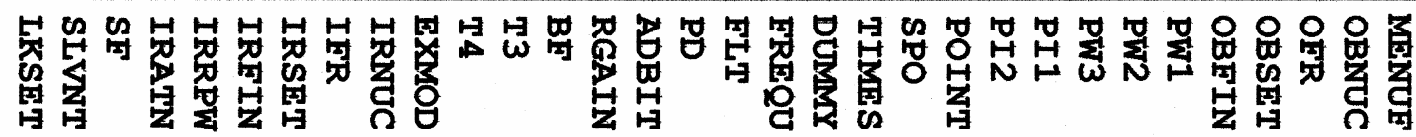

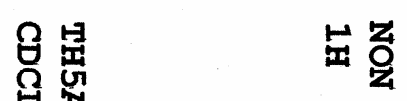

画弿

$\omega$

กิ

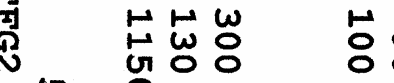

G G

씰

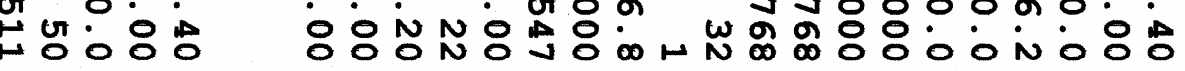

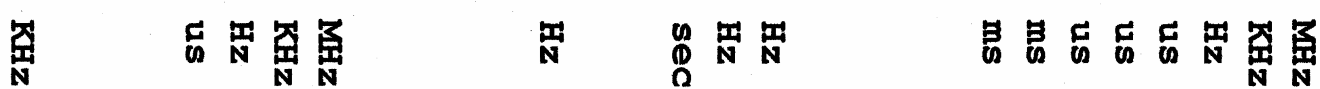

Figure 1. ${ }^{1} \mathrm{H}-\mathrm{NMR}$ spectrum of compound 4 


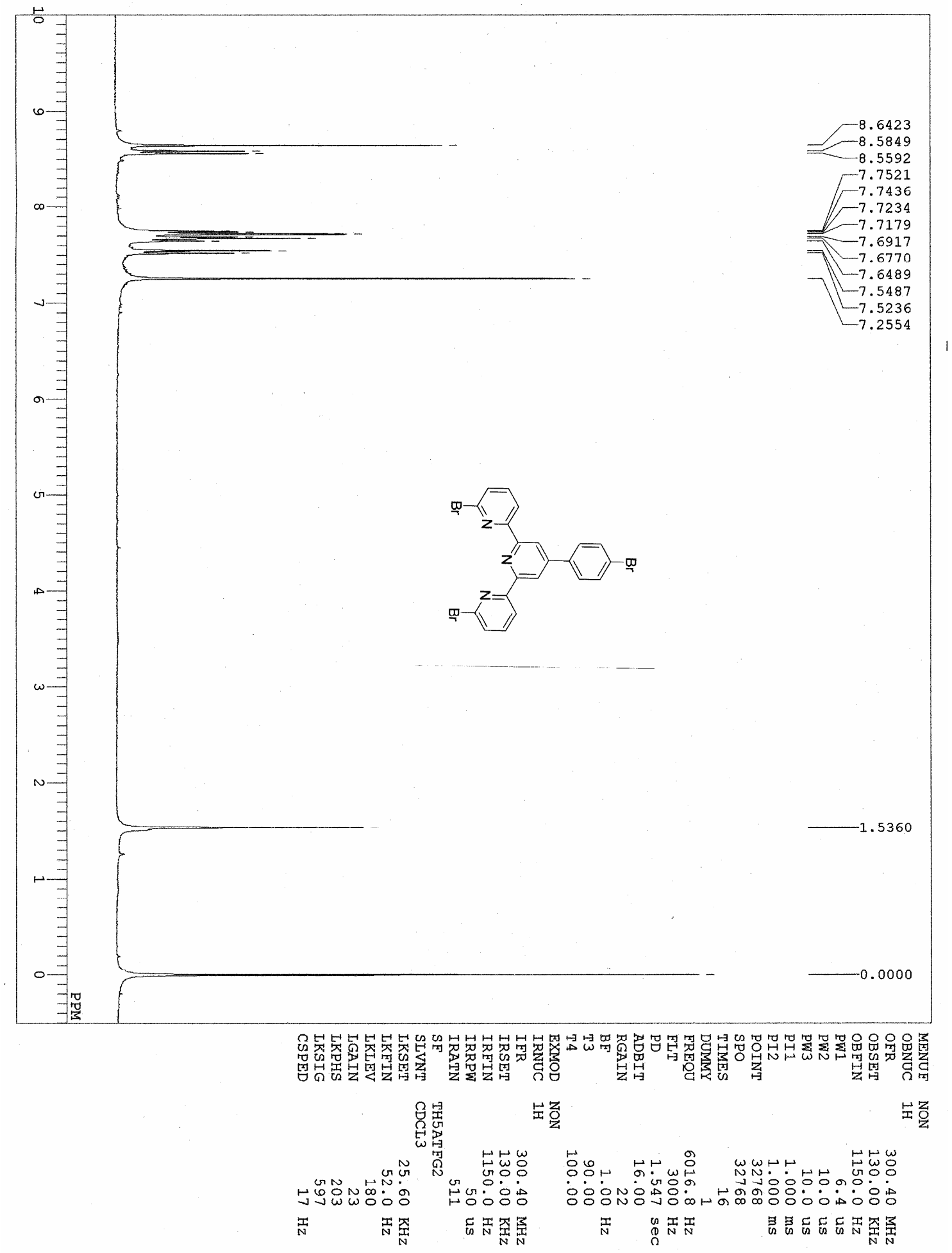

Figure 2. ${ }^{1} \mathrm{H}-\mathrm{NMR}$ spectrum of compound 5 


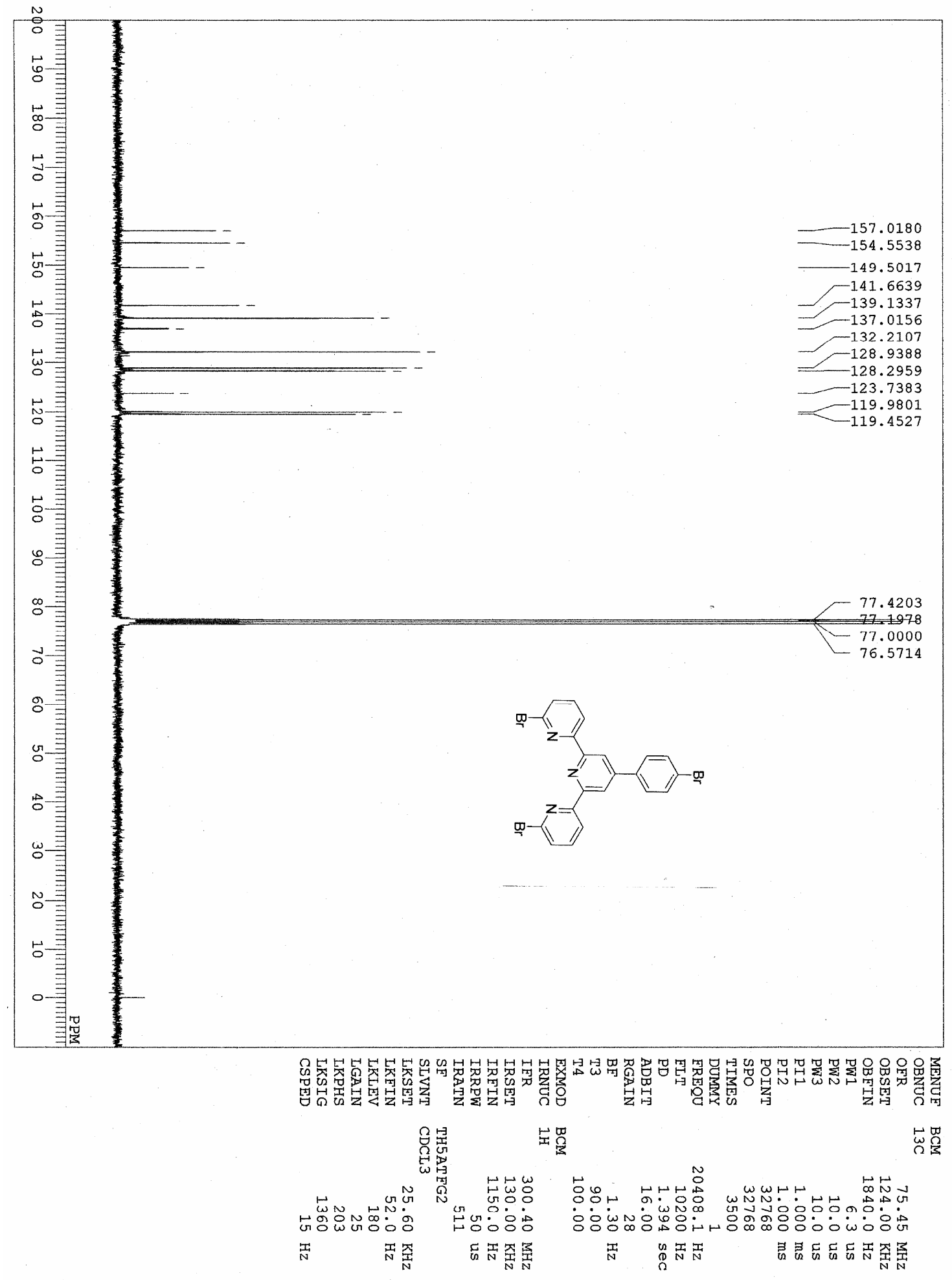

Figure 3. ${ }^{13} \mathrm{C}-\mathrm{NMR}$ spectrum of compound 5 


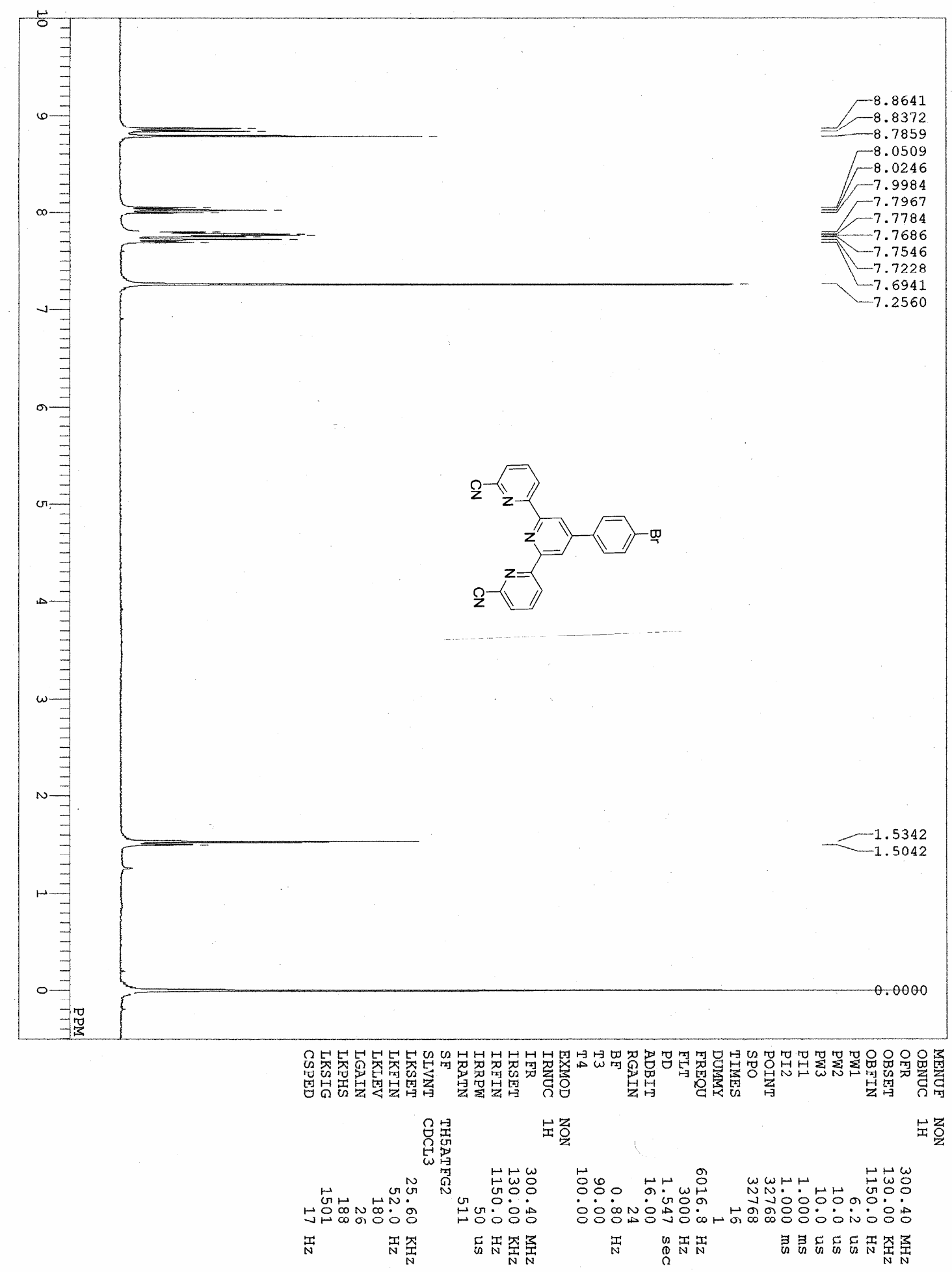

Figure 4. ${ }^{1} \mathrm{H}-\mathrm{NMR}$ spectrum of compound 7 


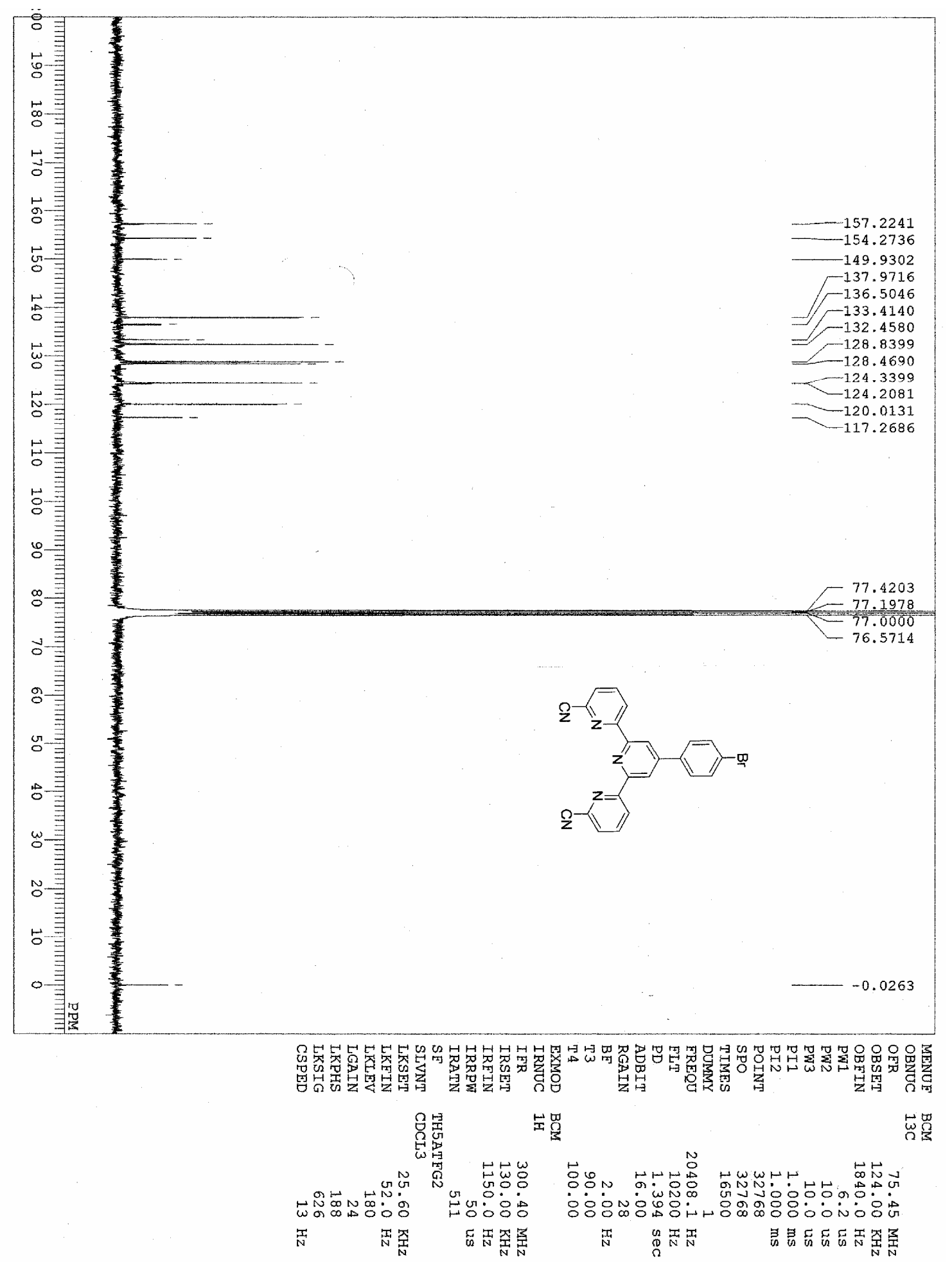

Figure 5. ${ }^{13} \mathrm{C}-\mathrm{NMR}$ spectrum of compound 7 


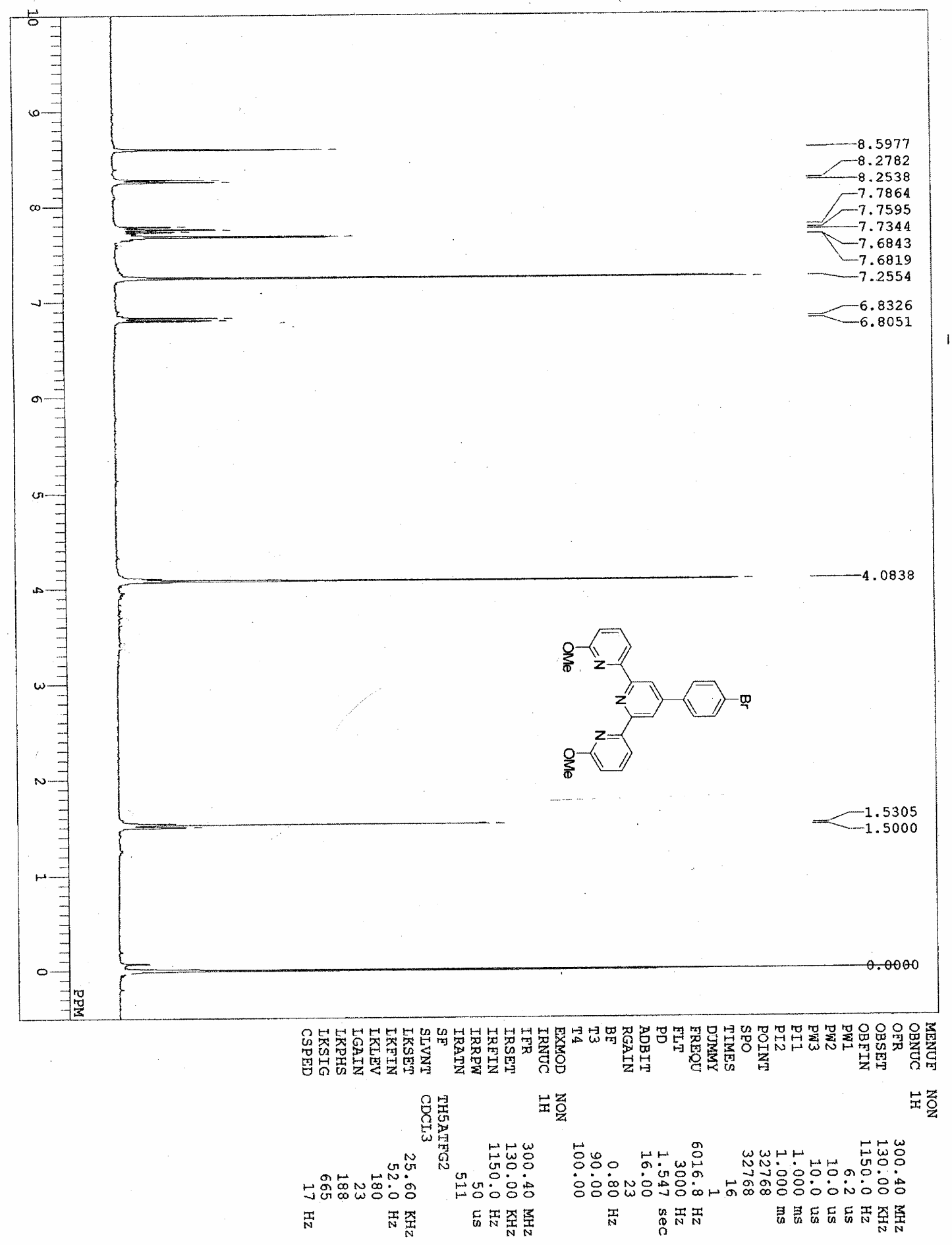

Figure 6. ${ }^{1} \mathrm{H}-\mathrm{NMR}$ spectrum of compound $\mathbf{8}$ 


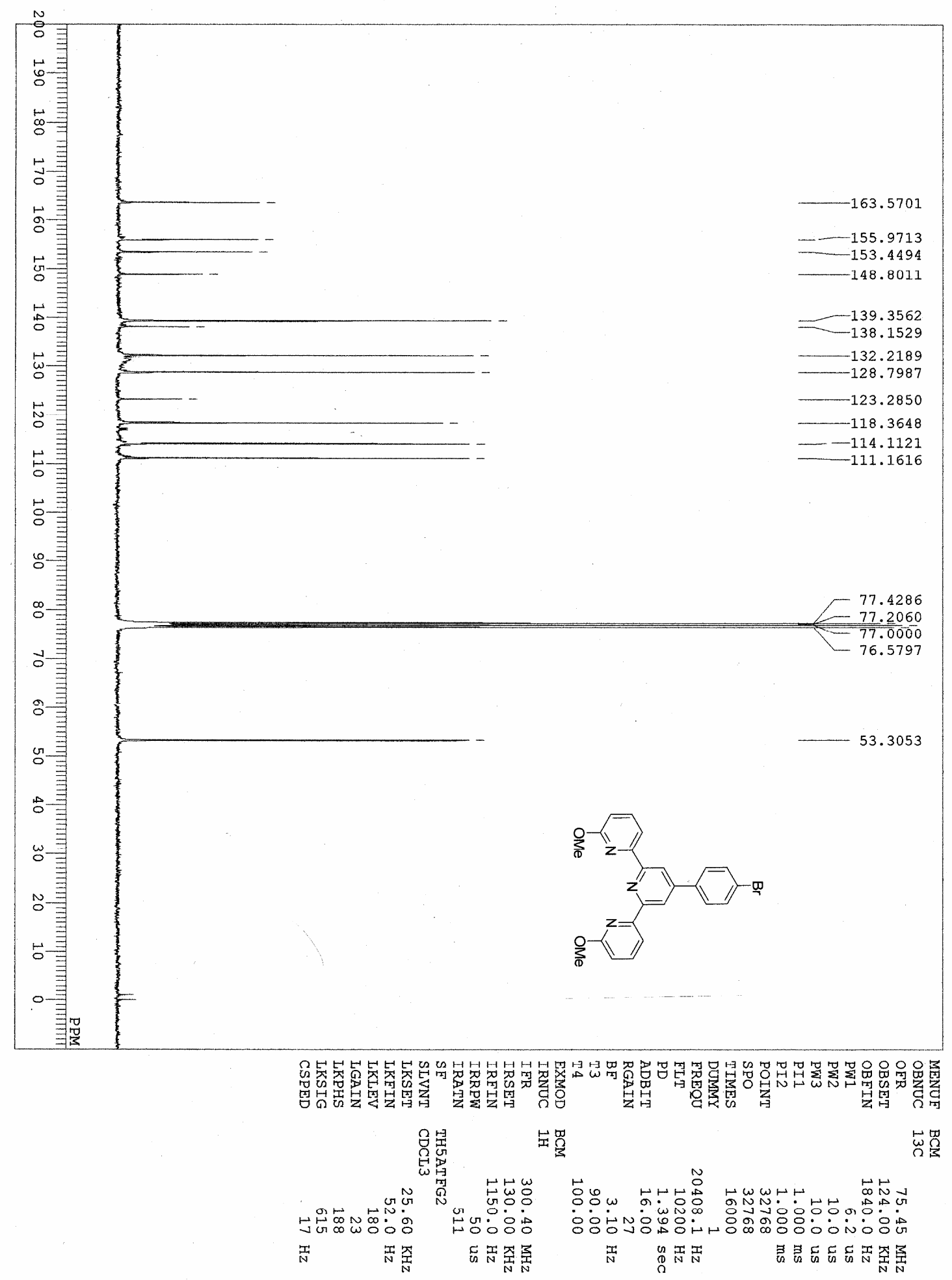

Figure 7. ${ }^{13} \mathrm{C}$-NMR spectrum of compound 8 


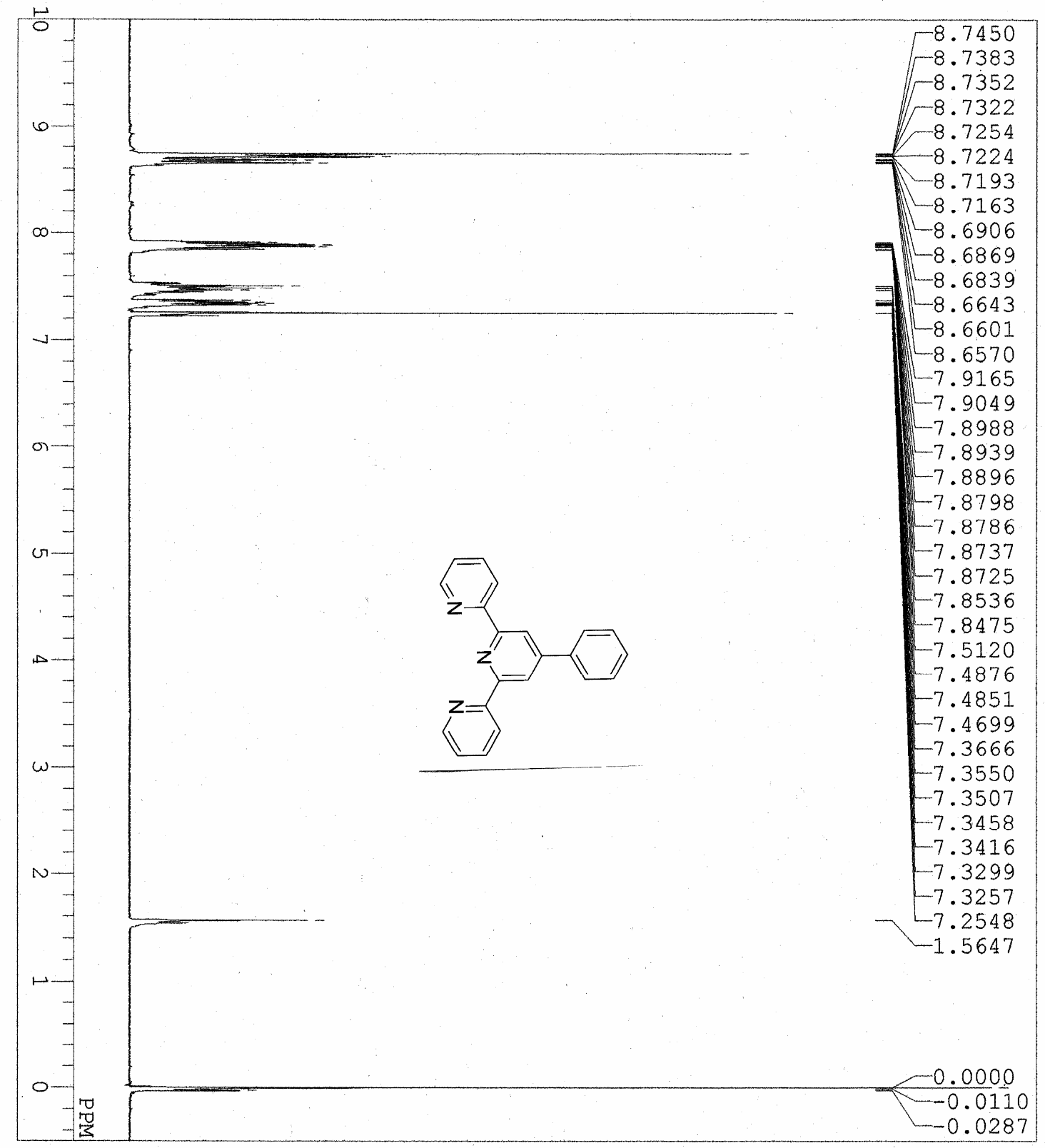

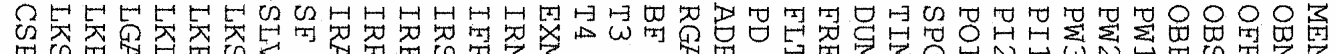

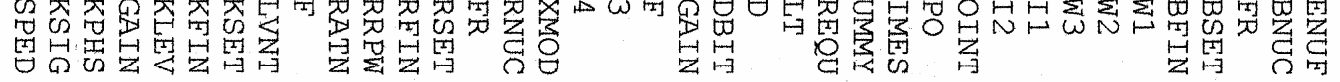

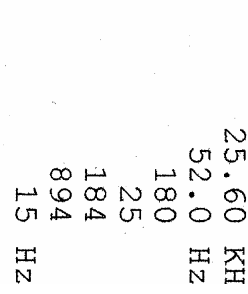

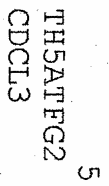
点另

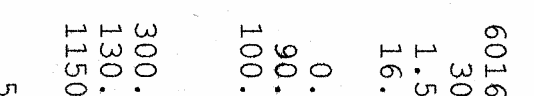

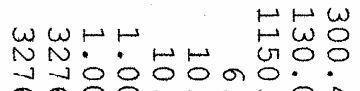 जज:
范界甾室

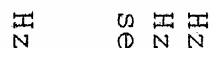

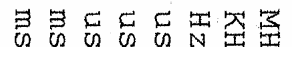

品吕

Figure 8. ${ }^{1} \mathrm{H}-\mathrm{NMR}$ spectrum of compound $\mathbf{1 2}$ 


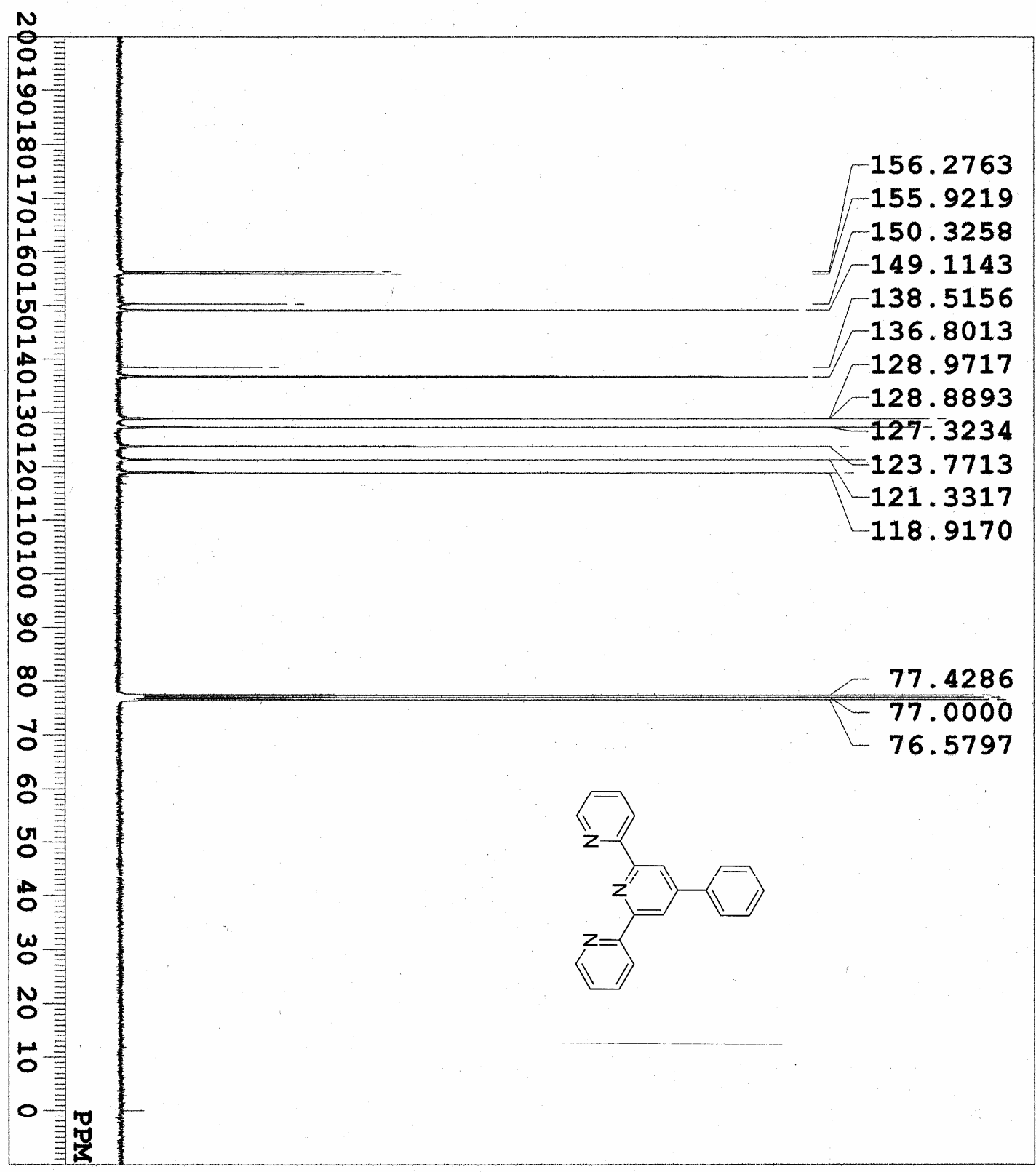

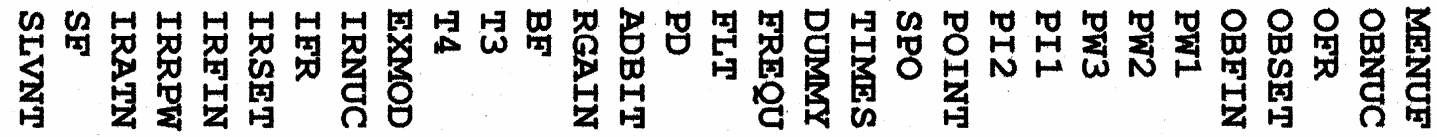

8 每苗骂

莕骂

燢

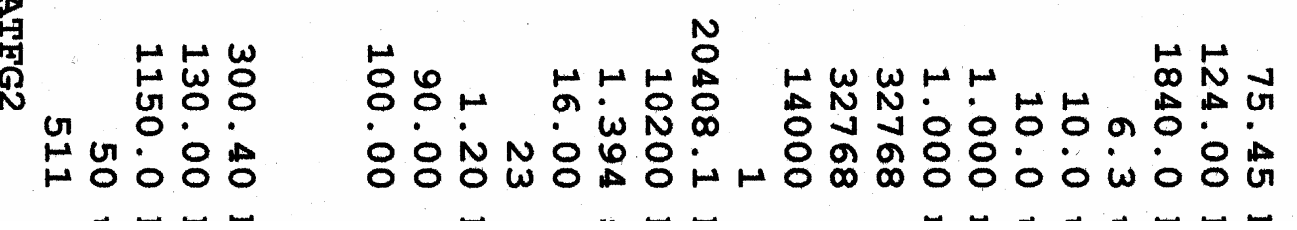

Figure 9. ${ }^{13} \mathrm{C}-\mathrm{NMR}$ spectrum of compound $\mathbf{1 2}$ 


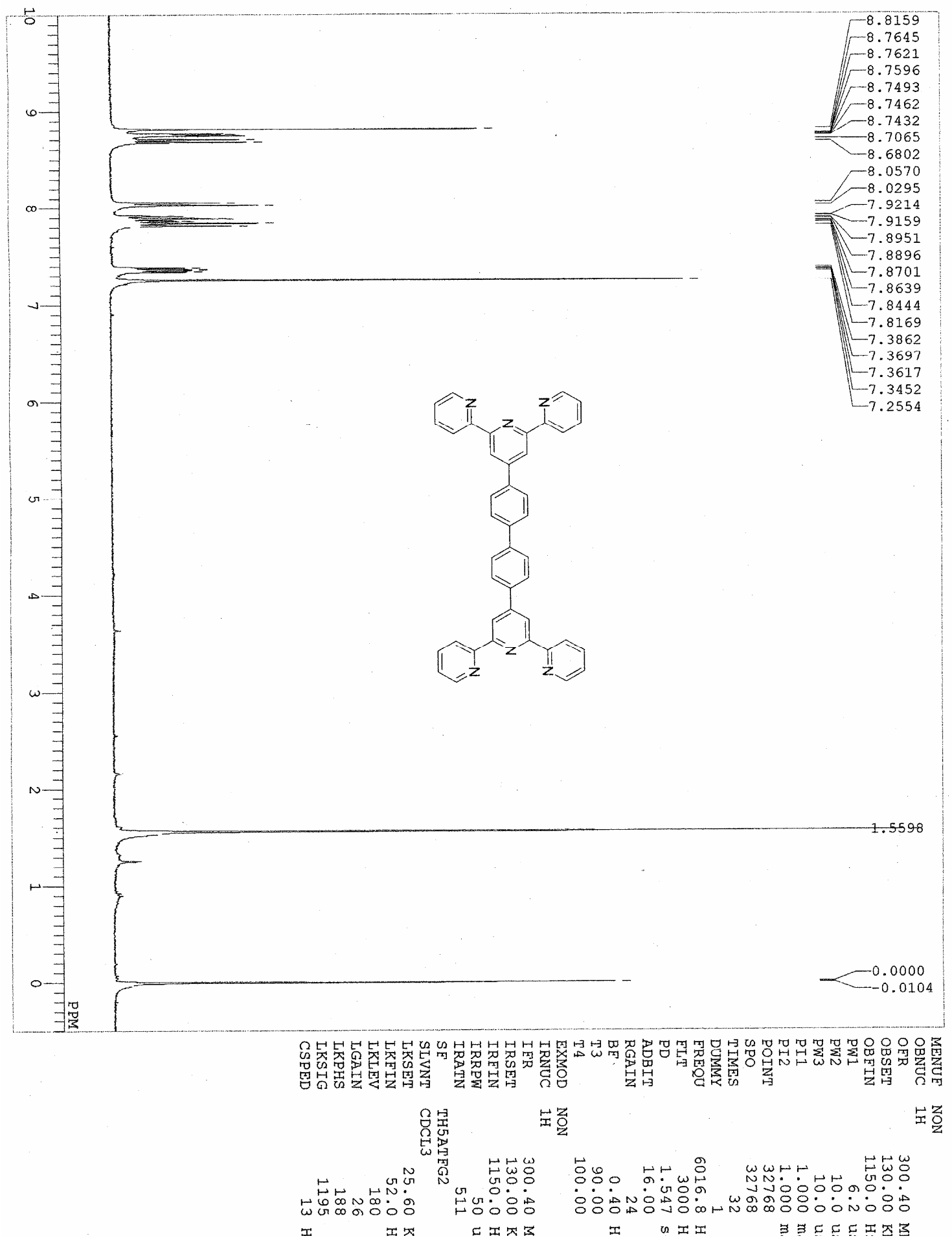

Figure 10. ${ }^{1} \mathrm{H}-\mathrm{NMR}$ spectrum of compound $\mathbf{1 4 a}$ 


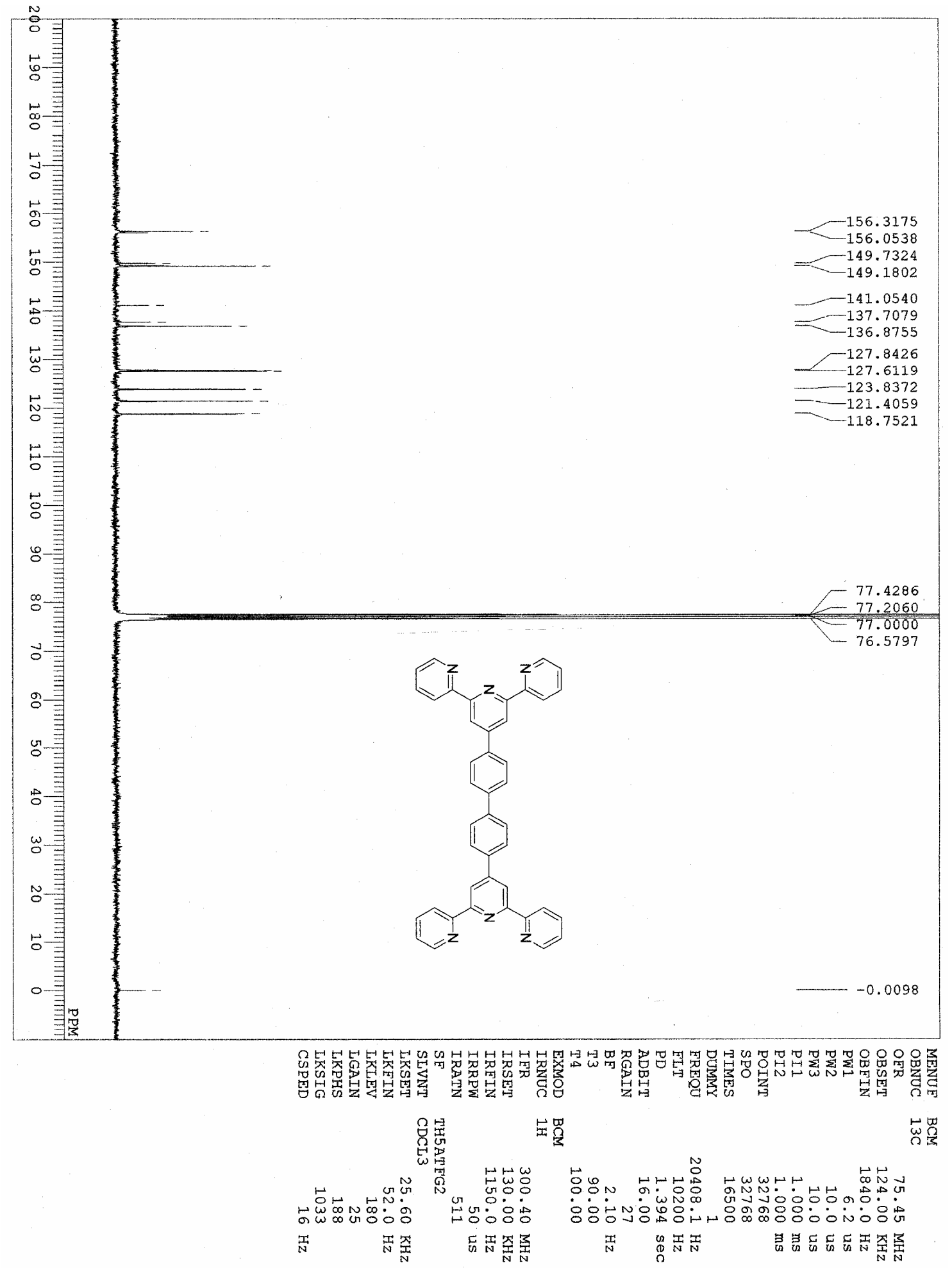

Figure 11. ${ }^{13} \mathrm{C}$-NMR spectrum of compound 14a 


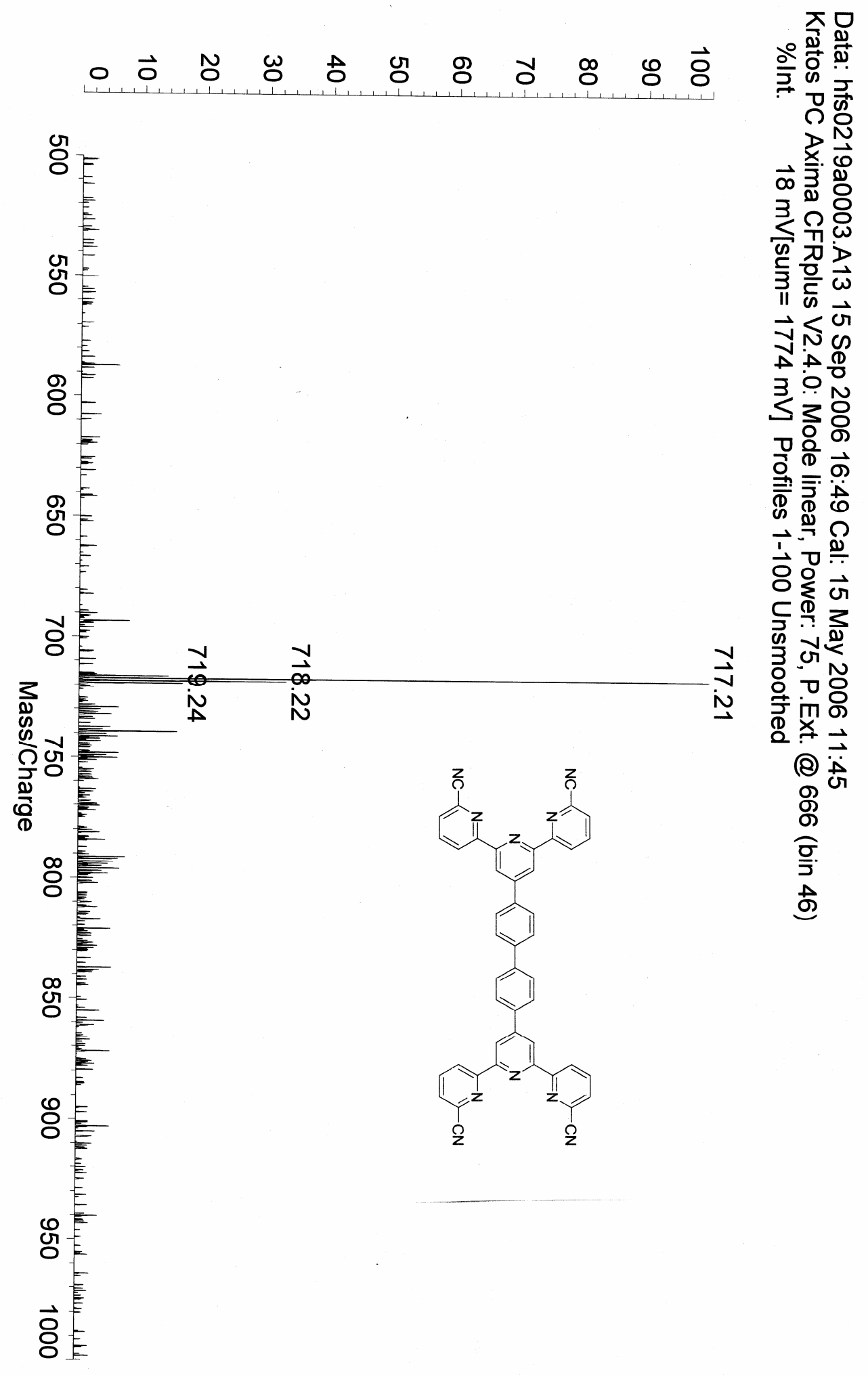

Figure 12. MS spectrum of compound 14b 


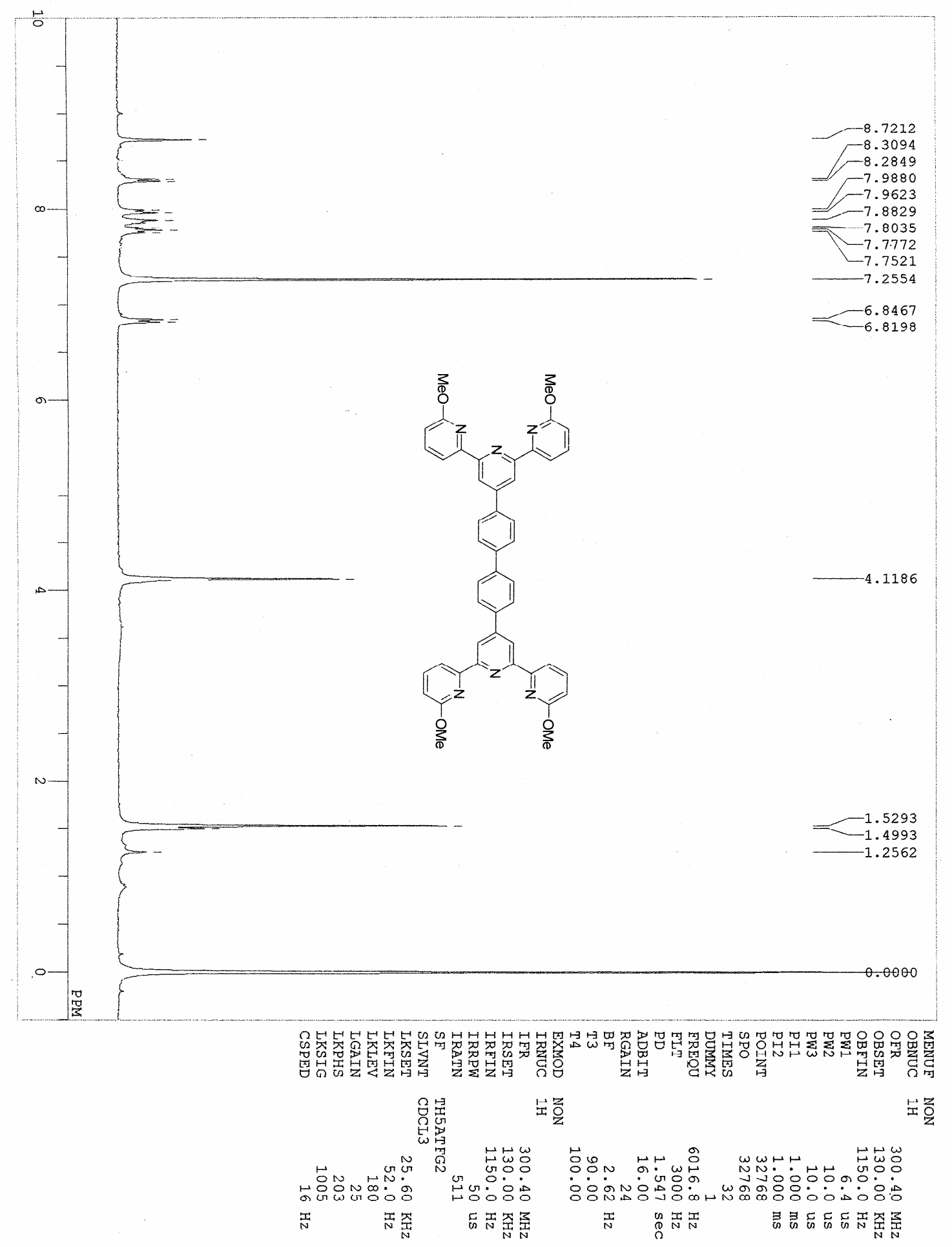

Figure 13. ${ }^{1} \mathrm{H}-\mathrm{NMR}$ spectrum of compound $\mathbf{1 4 c}$ 


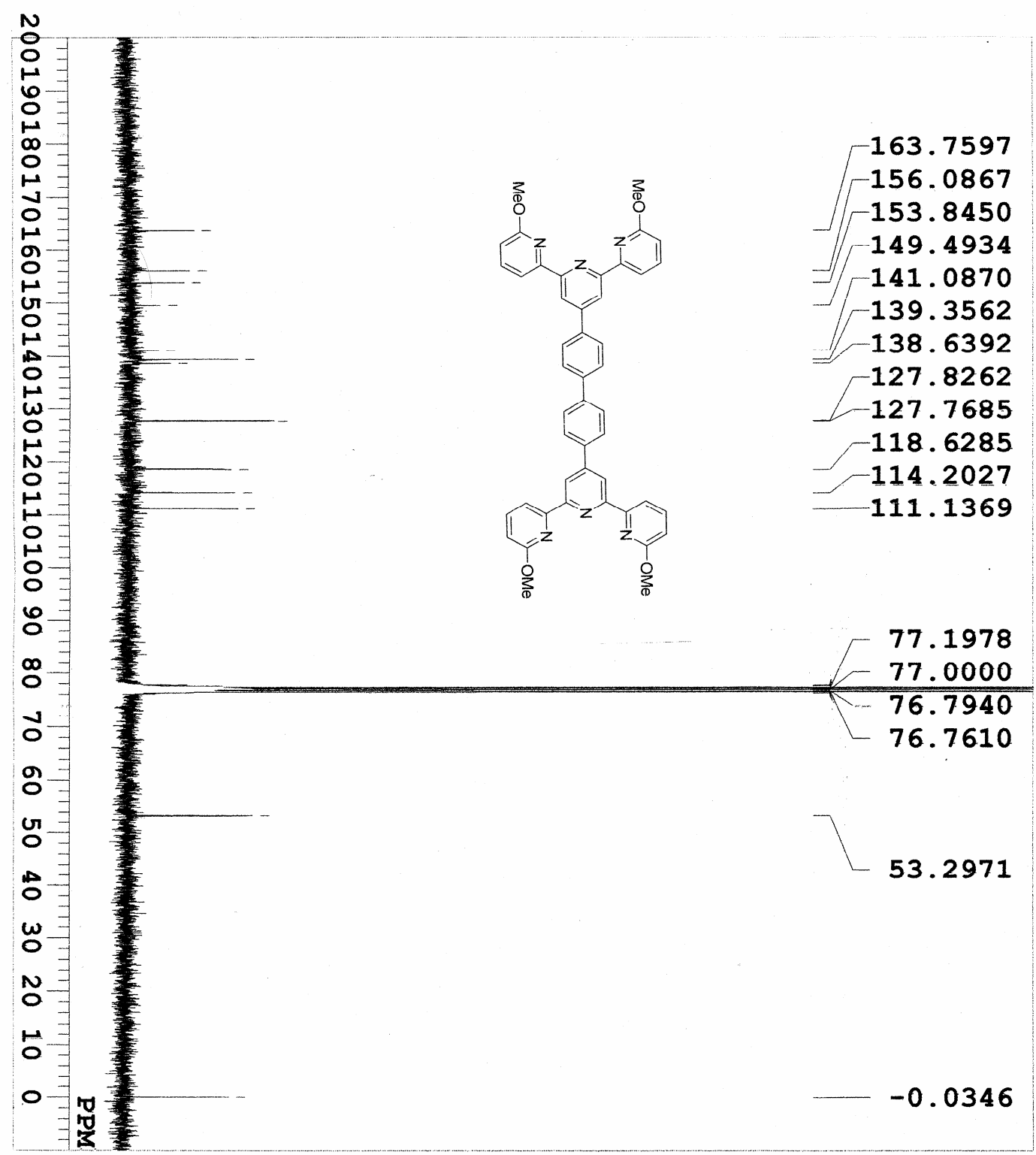

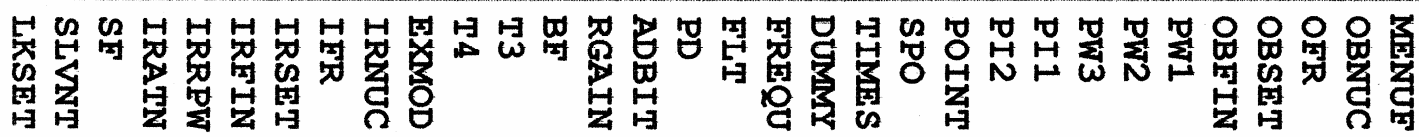

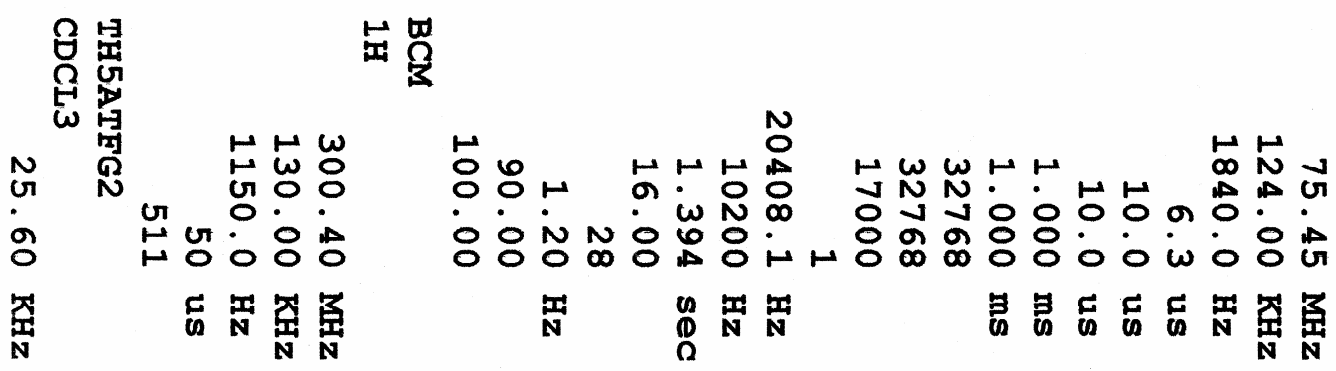

Figure 14. ${ }^{13} \mathrm{C}-\mathrm{NMR}$ spectrum of compound $14 \mathrm{c}$ 


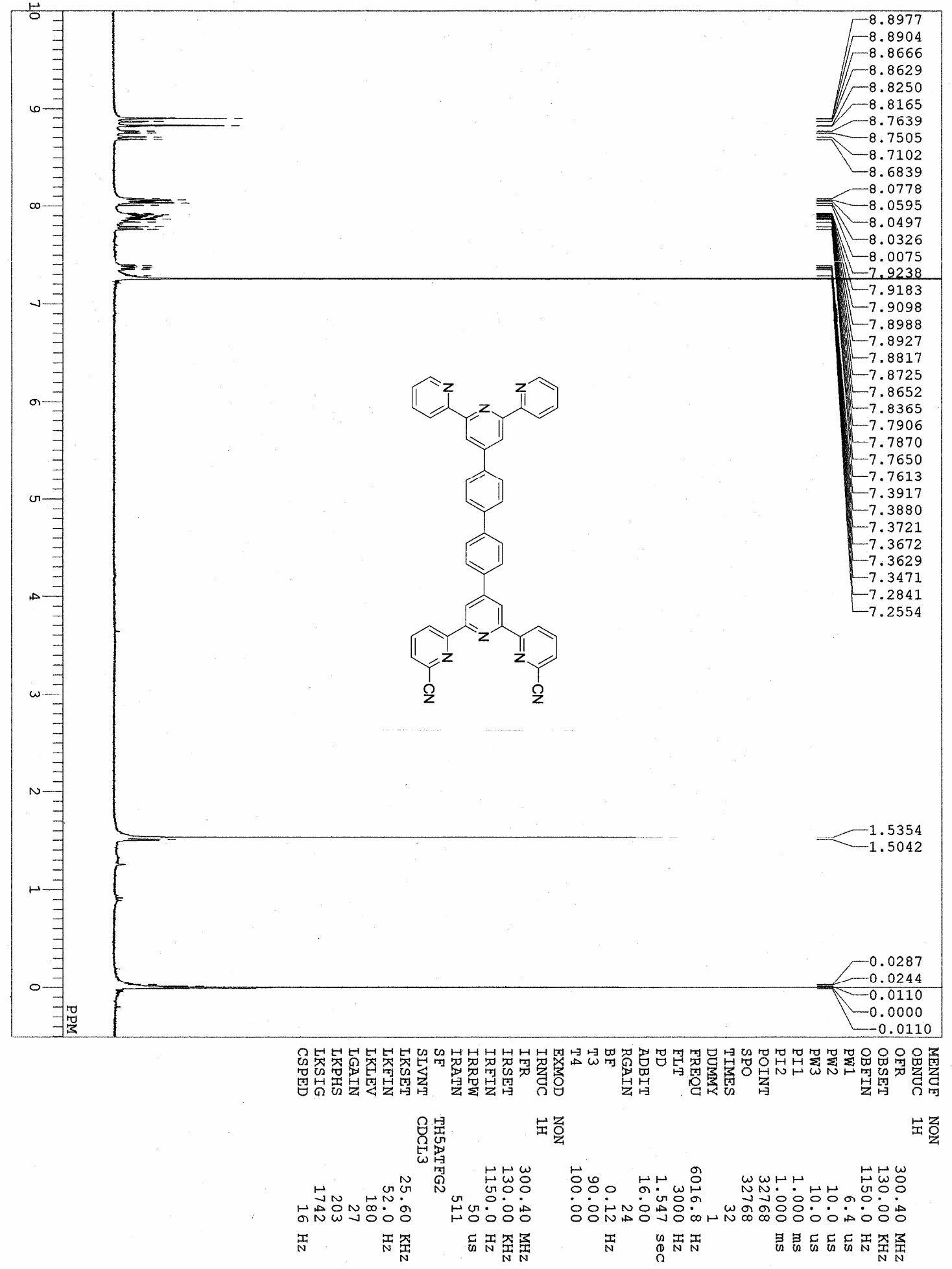

Figure 15. ${ }^{1} \mathrm{H}-\mathrm{NMR}$ spectrum of compound 15a 


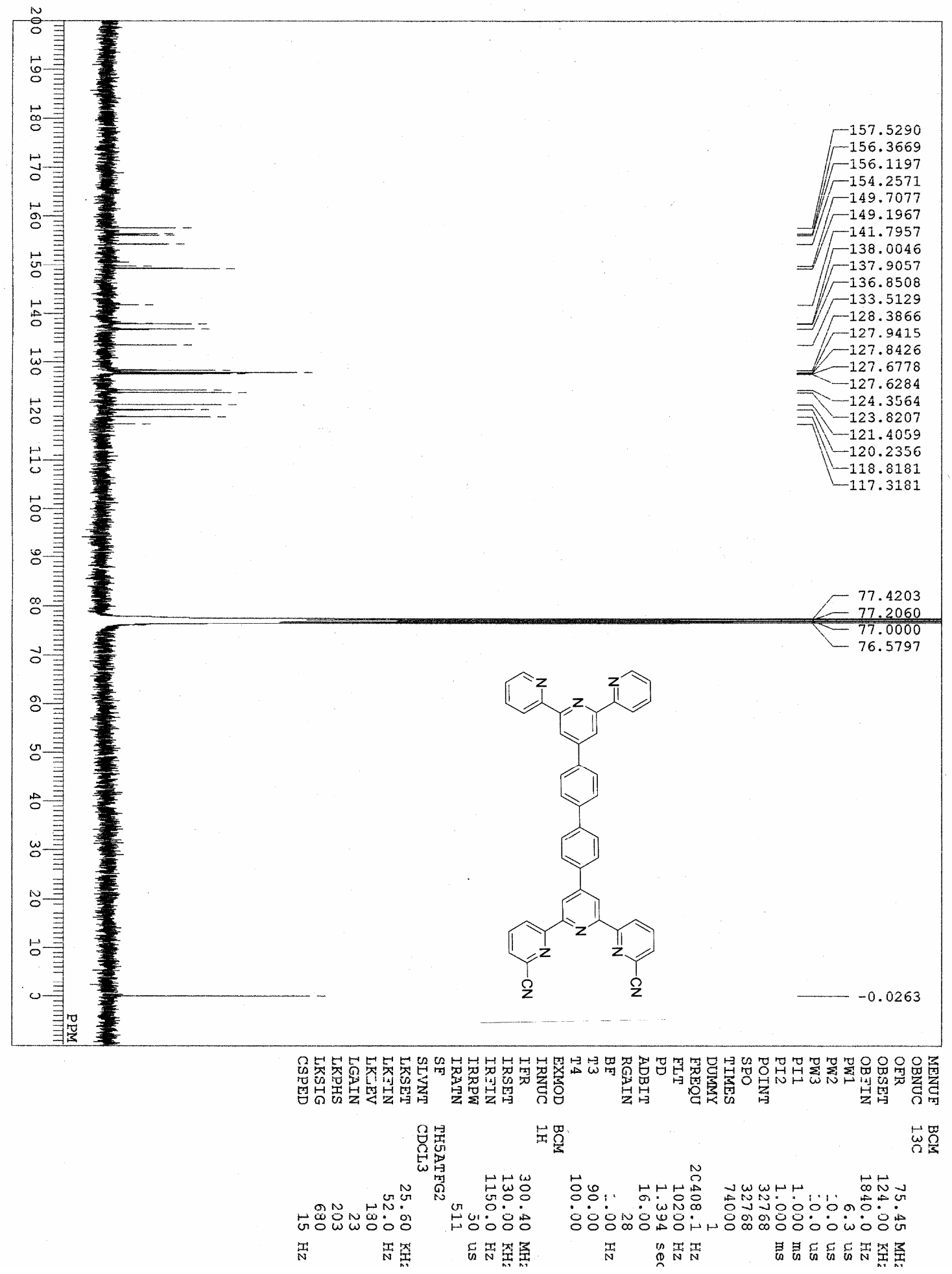

Figure 16. ${ }^{13} \mathrm{C}-\mathrm{NMR}$ spectrum of compound 15a 


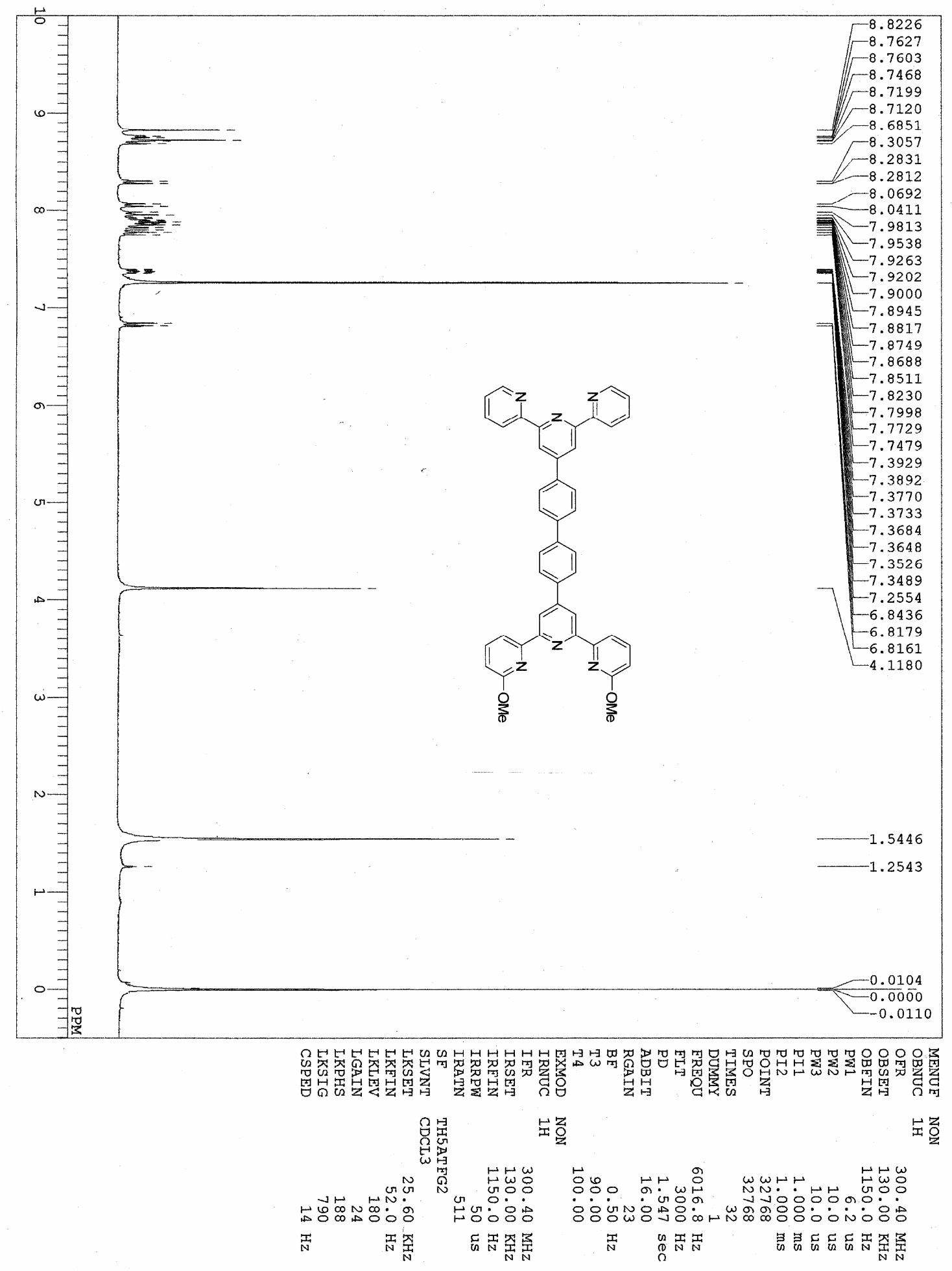

Figure 17. ${ }^{1} \mathrm{H}-\mathrm{NMR}$ spectrum of compound $\mathbf{1 5 b}$ 


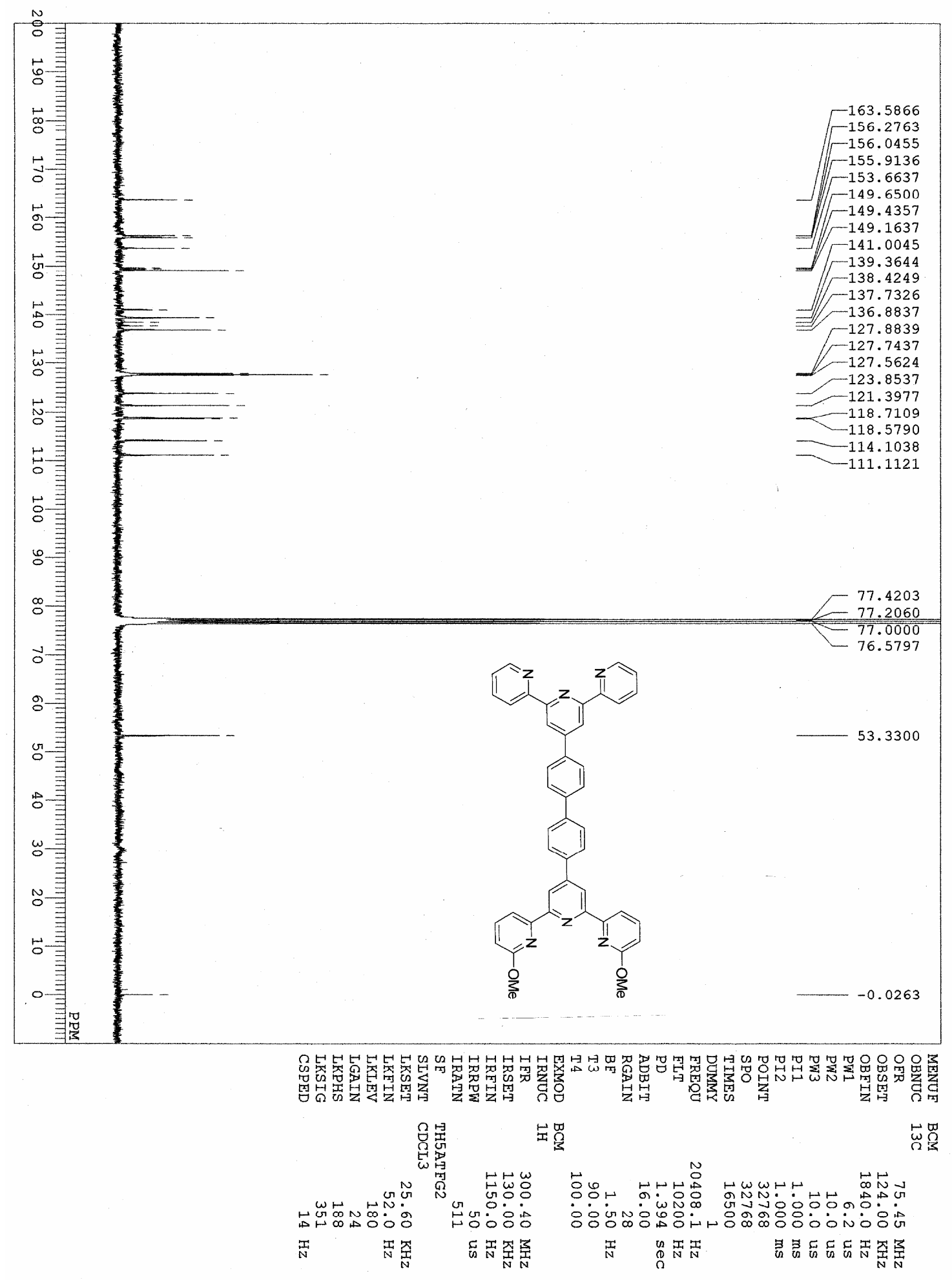

Figure 18. ${ }^{13} \mathrm{C}-\mathrm{NMR}$ spectrum of compound $\mathbf{1 5 b}$ 


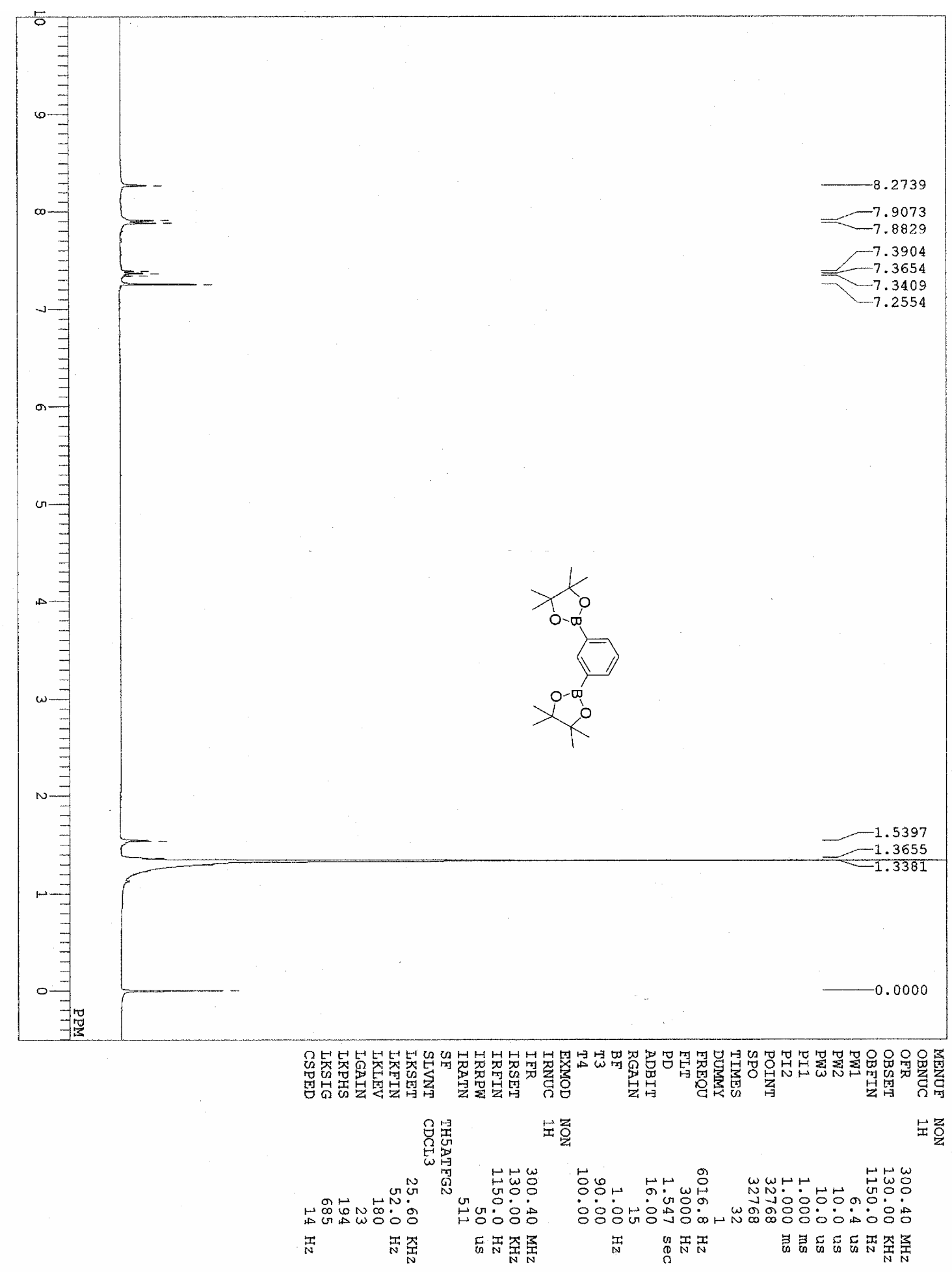

Figure 19. ${ }^{1} \mathrm{H}-\mathrm{NMR}$ spectrum of compound $\mathbf{1 7}$ 


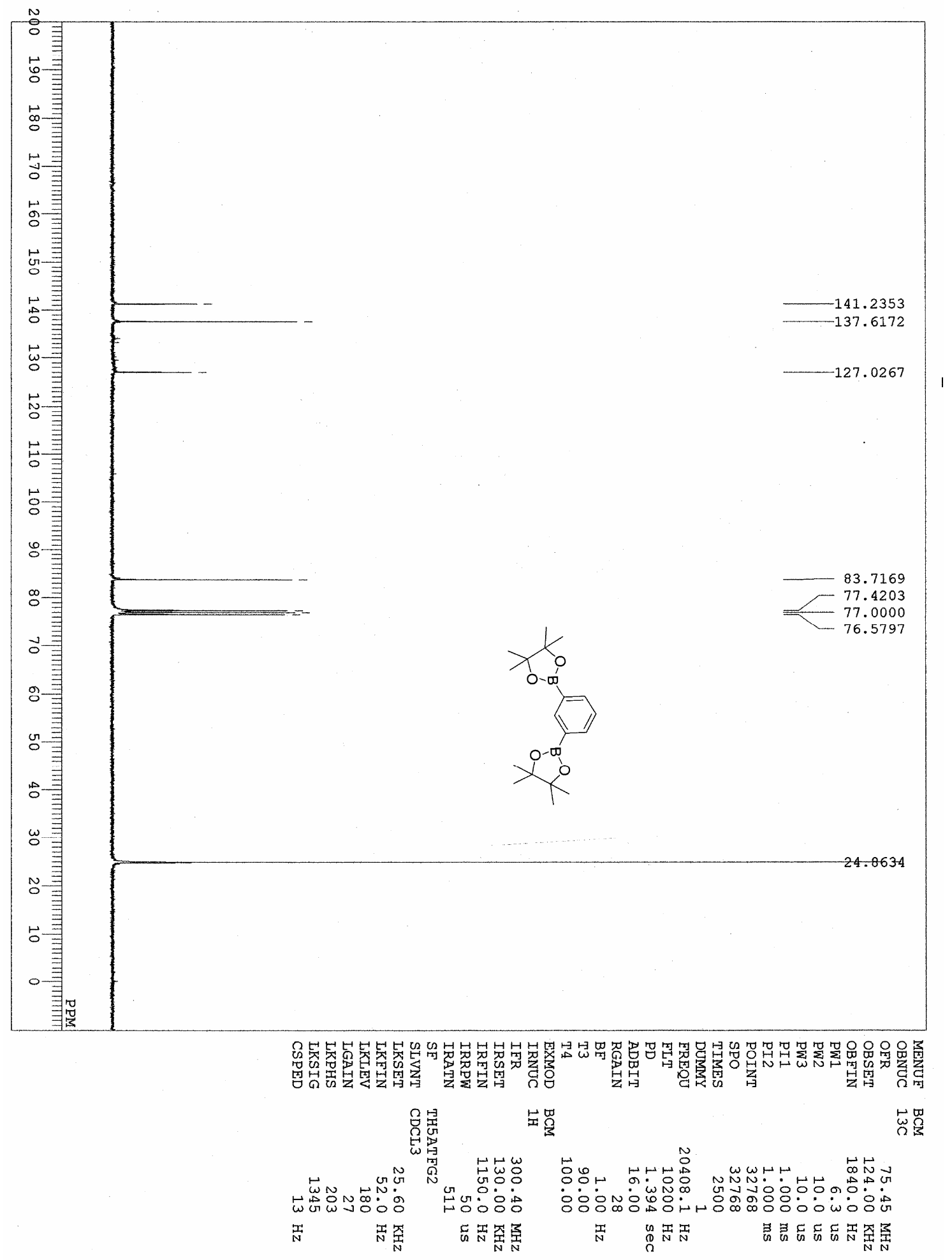

Figure 20. ${ }^{13} \mathrm{C}-\mathrm{NMR}$ spectrum of compound $\mathbf{1 7}$ 


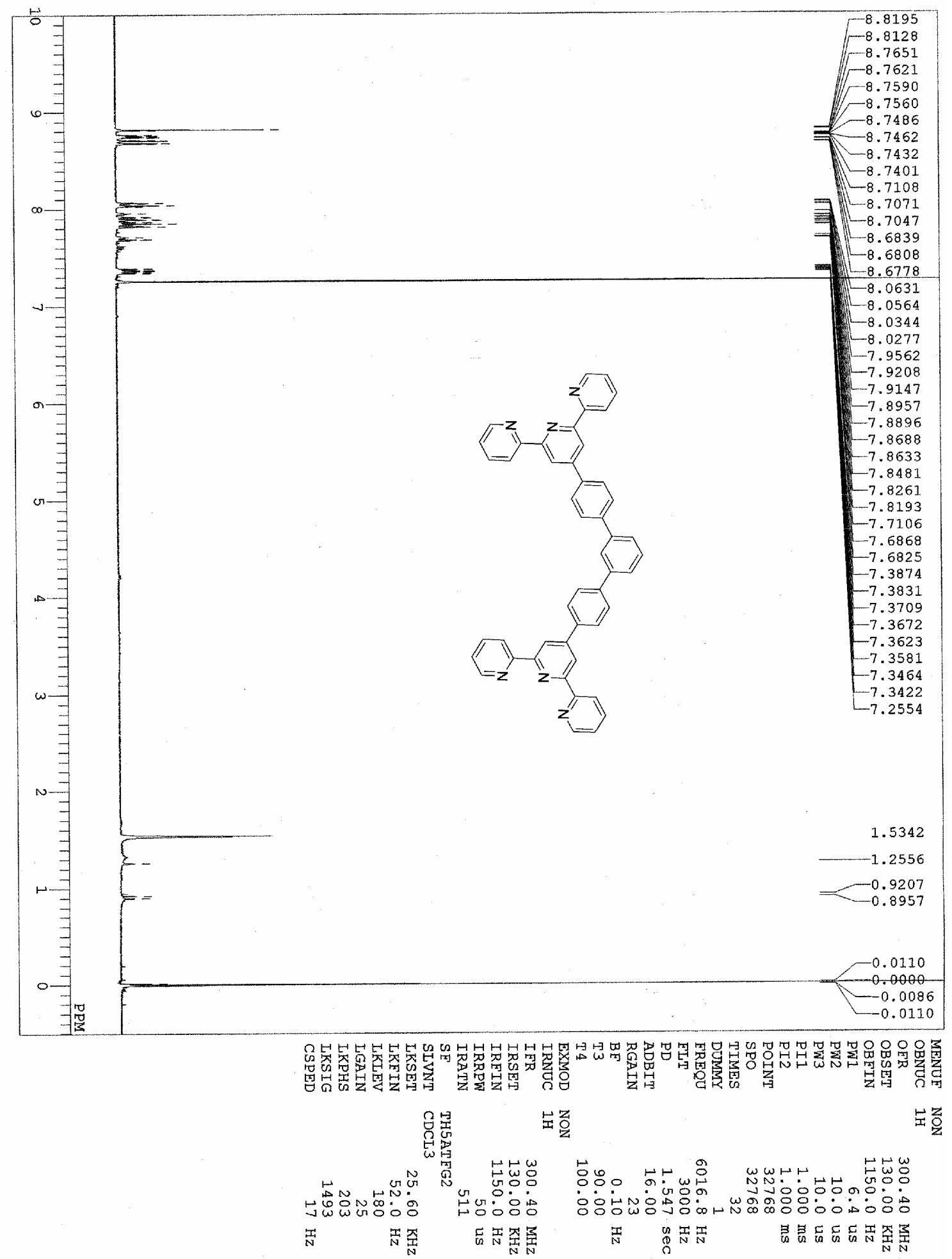

Figure 21. ${ }^{1} \mathrm{H}-\mathrm{NMR}$ spectrum of compound 18a 


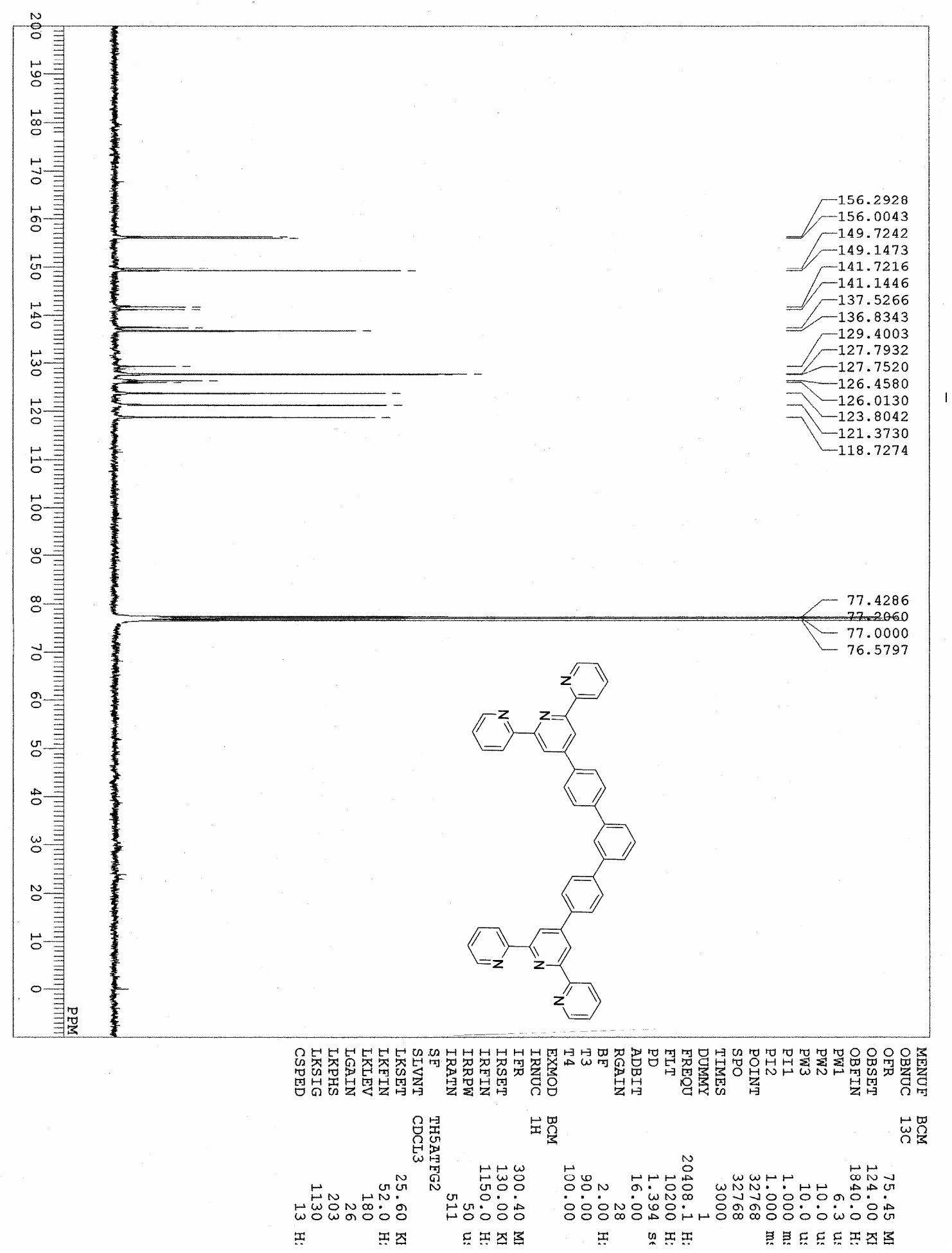

Figure 22. ${ }^{13} \mathrm{C}$-NMR spectrum of compound 18a 


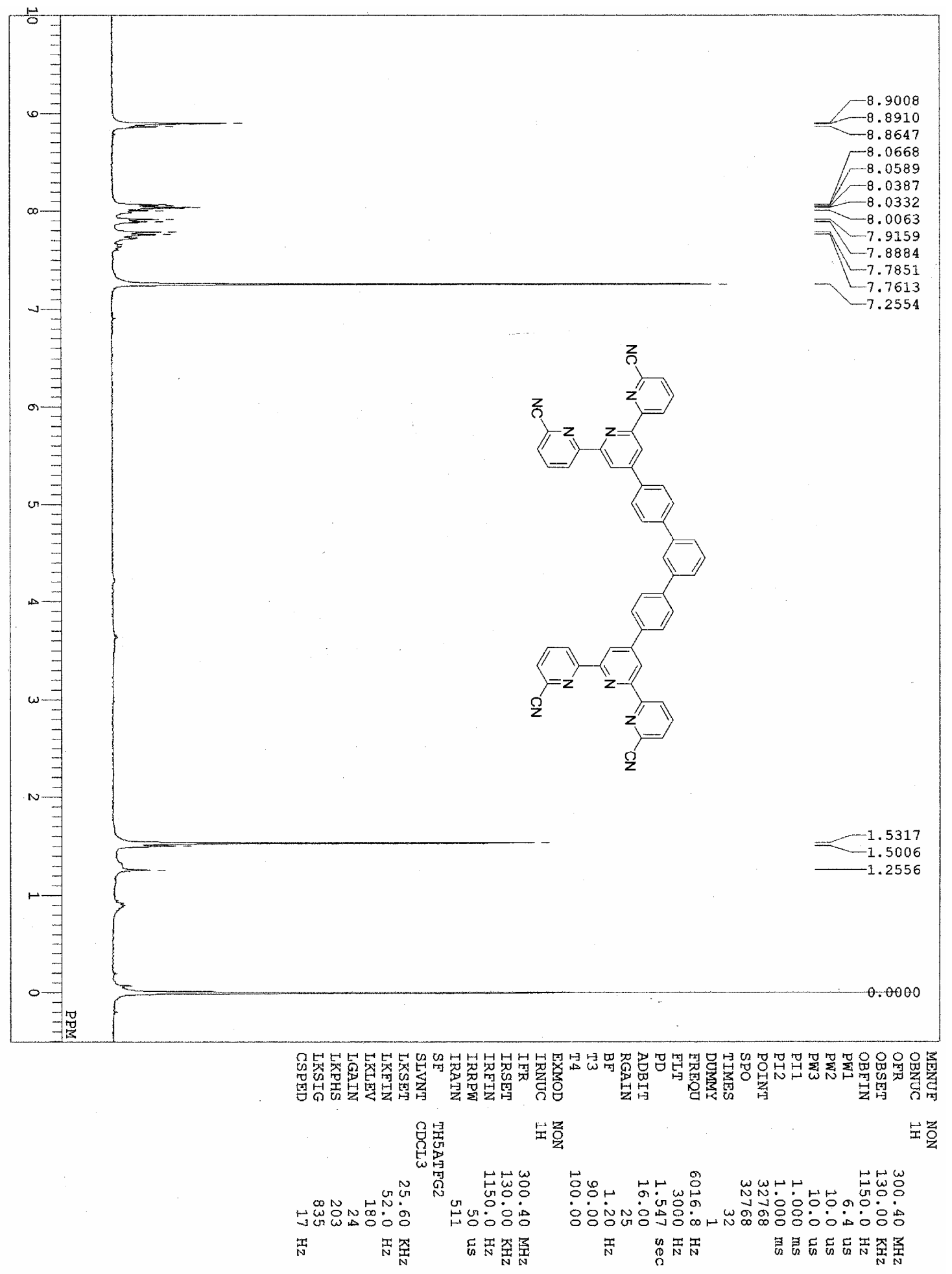

Figure 23. ${ }^{1} \mathrm{H}-\mathrm{NMR}$ spectrum of compound $\mathbf{1 8 b}$ 


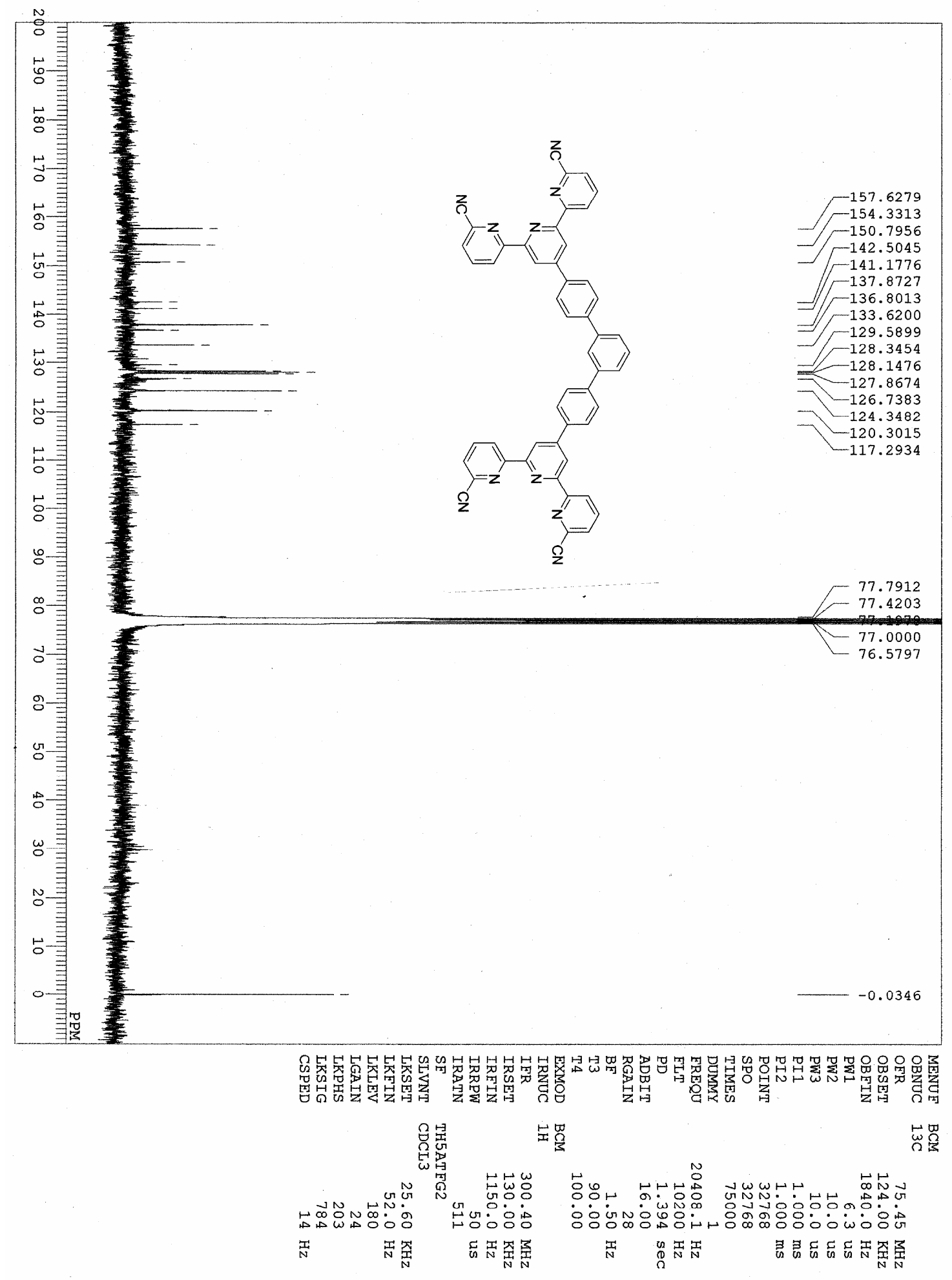

Figure 24. ${ }^{13} \mathrm{C}$-NMR spectrum of compound $\mathbf{1 8 b}$ 


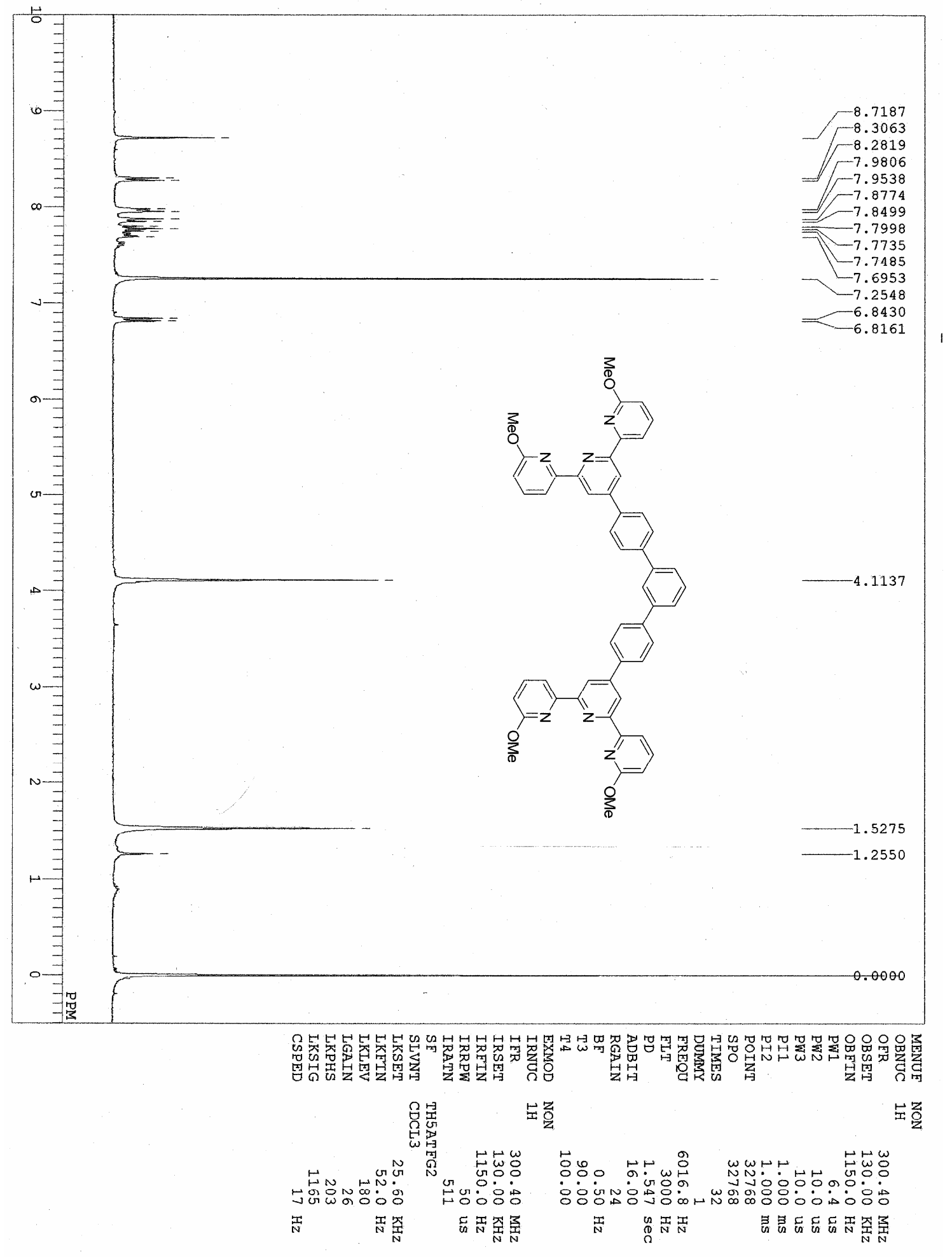

Figure 25. ${ }^{1} \mathrm{H}-\mathrm{NMR}$ spectrum of compound 18c 


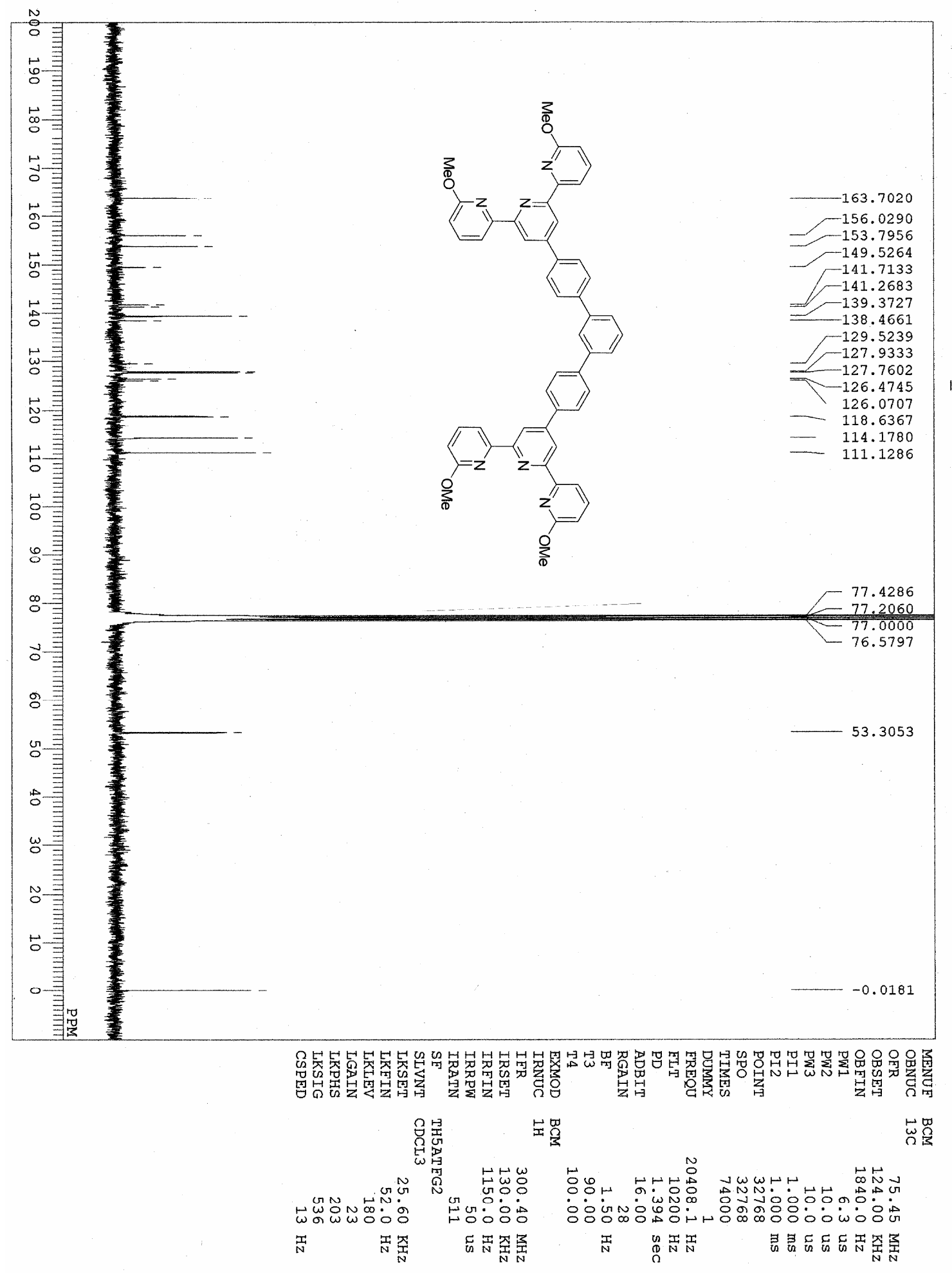

Figure 26. ${ }^{13} \mathrm{C}-\mathrm{NMR}$ spectrum of compound $\mathbf{1 8 c}$ 